\title{
UNA NUEVA FUENTE DE POLIFONÍA ANTIGUA EN LA PENÍNSULA IBÉRICA. EL MANUSCRITO 98.28 DE LA BIBLIOTECA CAPITULAR DE TOLEDO $(E-T c)$
}

\author{
A NEW SOURCE OF NOTRE DAME POLYPHONY FROM SPAIN. THE \\ MUSIC MANUSCRIPT 98.28 FROM TOLEDO, BIBLIOTECA CAPITULAR $(E-T C)$
}

Santiago Galán Gómez

Universitat Autònoma de Barcelona ${ }^{1}$

\begin{abstract}
Resumen:
Con este trabajo presentamos una colección de piezas de la Escuela de Notre Dame conservadas en el archivo de la Biblioteca Capitular de Toledo, únicamente citada anteriormente pero no descrita. Constituye una importante aportación al repertorio de polifonía antigua conservada en España, especialmente por la presencia de una versión a tres voces del hoquetus In seculum, así como de un nuevo texto poético, Agmina malicie junto con el conocido Agmina milicie. El estudio codicológico, textual, musical y de notación permite proponer un origen de copia francés para la colección, y datar su realización en los primeros años del siglo XIV. Se puede definir la fuente como una "copia terminal” de música de Notre Dame, pero todavía utilizable en la práctica musical dada la sincronización de las voces en el manuscrito.
\end{abstract}

Palabras clave:

Toledo, Notre Dame, polifonía antigua, hoquetus, In seculum, motetes.

Abstract:

With this paper we present a new source of Notre Dame polyphonic pieces held at the Biblioteca Capitular in Toledo, Spain, which remained unstudied until now. This is an important addition to the repertory of this music preserved in Spanish sources, thanks especially to the inclusion of a three-voice setting of the In speculum hoquetus and a new poetic text, Agmina malicie alongside the well-known Agmina milicie. The study of the codex, texts, music and notation point to a French origin of the source, copied around 1300, which can be defined as a "terminal" copy of Notre Dame music, but still conceived as a performing source, given the synchronization of all the voices in the manuscript.

Keywords:

Toledo, Notre Dame, polyphony, hocket, In seculum, motet.

1 El presente texto es reelaboración de mi Trabajo de Máster realizado en la Universitat Autònoma de Barcelona, bajo la dirección de la profesora Maricarmen Gómez Muntané, para quien va todo mi agradecimiento por su generosa dedicación y sincero interés. Se realizó una presentación preliminar de las conclusiones en la Medieval and Renaissance Music Conference 2011 celebrada en Barcelona, bajo el título “A New Source of Notre Dame Polyphony from Spain. The Music Manuscript 98.28 from Toledo, Biblioteca Capitular", en sesión del 6 de julio. El acceso al manuscrito me fue facilitado amablemente por el personal del Archivo Capitular, en especial por el Técnico del Archivo y Biblioteca Capitulares Don Alfredo Rodríguez, a quien agradezco su asistencia. 


\section{DESCRIPCIÓN CODICOLÓGICA}

El manuscrito conservado en la Biblioteca Capitular de Toledo con la signatura BCT 98.28 (olim 9-17; olim 22-13), ${ }^{2}$ al que en adelante nos referiremos con la sigla E-Tc 98.28, ${ }^{3}$ consiste en un códice facticio, encuadernado en cuero rojizo sobre tabla, identificado en el tejuelo como "Computus Episcopi Linconiensis et secretis / secretorum Aristotelis. Ms". Contiene una recopilación de textos de diversos autores (Grosseteste, Campanus de Novara, Johannes de Sacrobosco, Alfarabi, Alexander de Villa Dei) sobre cómputo y astronomía, así como la obra De consolatione anime de Boecio, un Liber Decretorum, dos calendarios litúrgicos, y una sección final con música relacionada con la Escuela de Notre Dame.

El volumen se inicia con cuatro guardas sin numerar a las que siguen 241 folios numerados en época moderna, y finaliza con otras cuatro guardas no numeradas. En algunas de éstas se adivinan muy tenues restos de notación musical cuadrada de gran tamaño, seguramente de un antiguo cantoral reutilizado en la encuadernación. Los folios de vitela del códice, de $127 \mathrm{~mm}$ de alto por $121 \mathrm{~mm}$ de ancho, se organizan en fascículos identificados alfabéticamente en tinta. Acabada la serie en la letra "z", prosigue otra sucesión incompleta con las letras "g", "e”, y finalmente el fascículo "h" (folios 229 a 242) el cual cierra el códice y contiene la música (notada en los folios $230 \mathrm{r}$ al 239r). ${ }^{4}$

Este fascículo final consta de siete bifolios organizados según una estructura "pelo contra pelo", excepto el bifolio 229-242, vacío, que invierte este orden. El contenido del fascículo en breve resumen es el siguiente:

- Folios 229r - 229v: vacíos.

- Folios 230r-231v: un conductus monofónico.

2 Citado por GÜMPEL en 1997 como E-Tc 98-28 en RISM B III, Vol. 5, Manuscripts from the Carolingian era up to c.1500 in the Czech Republic, Poland, Portugal and Spain, G. Henle Verlag München (1997), p.127-128. Una descripción del contenido completo del códice se puede consultar en el Catálogo Internacional de Manuscritos Científicos, en http://jordanus.org donde el códice consta con la referencia STOLC9828/00, así como en GONZÁLVEZ RUIZ, 2005: 148.

3 Las siglas usadas para las fuentes que se citan a lo largo del artículo son las siguientes: $\mathrm{F}$ - $\mathrm{Pa}$ 3517-18-París, Bibliothèque de 1'Arsenal, 3517-18; $D$-BAs 115-Bamberg, Staatsbibliothek, Lit. 115; $D$ - $B s b 8^{\circ}$ 225-Berlin Staatsbibliothek, lat. $8^{\circ} 225 ; F-B$ 716-Besançon, Bibliothèque Municipale, I, 716; F-BSM 148-Boulogne-sur-Mer, Bibliothèque Municipale, 148 (olim 119); GBCcc 8-Cambridge, Corpus Christi College, 8, guarda; I-CF56-Cividale del Friuli: Museo Archeologico Nazionale, codex LVI; F-Pn 13521-Paris, Bibliothèque Nationale de France, nouv. acq. fr. 13521 (Chansonnier de La Clayette); GB-Ctc 0.2.1-Cambridge, Trinity College, 0.2.1; D-DS 3471-Darmstadt, Hessische. Landesbibliothek, 3471 (olim 3317 + 3471-2); D-DO 882-Donaueschingen, Fürstliche Fürstenbergischen Hofbibliothek, 882; I-FI 29.1-Florencia, Biblioteca Mediceo-Laurenziana, Pluteus XXIX, I; F-Pn 24541-Paris, Bibliothèque Nationale de France, nouv. acq. fr. 24541; E-BUlh-Burgos, Real Monasterio de las Huelgas, codex s/n; GB-Lbl 2615-London, British Library, Egerton 2615; GB-Lbl 274-London, British Library, Egerton 274; GB-Lbl 30091-London, British Library, Add. 30091; GB-Lbl 978-London, British Library, Harley 978; GBLlp 522-London, Lambeth Palace, $522 ;$ F-Pn 814-Paris, Bibliotheque Nationale de France, f. fr. 814 (Manuscript du Roi); E-Mn 20486-Madrid, Biblioteca Nacional de España, 20486; F-Pm 307-Paris, Bibliothèque Mazarine, 307; F-Mo 196-Montpellier, Bibliothèque Inter-Universitaire, Section Médecine, H 196; D-Mbs 16444-Munich, Bayerische Staatsbibliothek, lat. 16444; D-Mbs 5539-Munich, Bayerische Staatsbibliothek, lat. 5539; GB-Ob 72-Oxford, Bodleian Library, Lyell 72; D-Sl 95-Stuttgart, Württembergische Landesbibliothek, H.B. I Ascet 95; F-Pn 15139-Bibliothèque Nationale de France, lat. 15139 (olim St. Victor 813); E-Tc 98.28-Toledo, Biblioteca Capitular, 98.28 (olim 9-17; 22-13); D-W 1099-Wolfenbüttel, Herzog August Bibliothek, Helmst 1099.

4 Esta serie incompleta parece apuntar a una serie de fascículos perdidos, aunque probablemente sin música, pues el fascículo "g" no la contiene, y el siguiente "h" es el que nos ocupa. 
- Folio 232r: vacío (con caja dibujada).

- Folios 232v - 239r: sección polifónica.

- Folios 239v-241r: vacíos.

- Folio 241v: rúbrica manuscrita.

- Folios 242r - 242v: vacíos.

Además de la numeración moderna a lápiz ya señalada, los folios 232r a 235r se encuentran numerados con tinta en el borde inferior derecho con cifras romanas de I a IIII según muestra la ilustración 1.

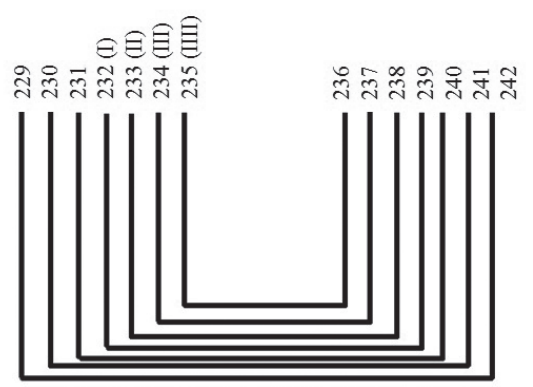

Ilustración 1.Estructura de E-Tc 98.28

La única referencia respecto a la procedencia del códice consiste en la rúbrica del folio $241 \mathrm{v}$, donde se lee: "este libro es delos que dexaron los arcedianos de Toledo don Diego et Don Vasco Ramirez de Guzman. Johannes Ruyz secretarius”. Diego Ramírez de Guzmán falleció en 1414 y fue cubiculario del Papa Benedicto XIII de Aviñón, así como arcediano de Toledo, cargo que obtuvo de dicho pontífice al retirarse este a Peñíscola. ${ }^{5}$ Su hermano Vasco, "hombre muy notable e gran letrado e de buena vida", le sucedió en este cargo de arcediano. Además de ser un destacado traductor de obras latinas, Vasco realizó diversas misiones en Roma, se incorporó al gremio de refrendarios pontificios, e incluso llegó a realizar gestiones diplomáticas en la corte francesa por encargo del rey castellano. Falleció el 6 de enero de $1439 .{ }^{6}$ A su muerte, y por encargo que había recibido de Benedicto XIII, Vasco entregó un pequeño lote de libros que había conservado en vida en nombre del Papa. En este lote figuraba el códice que nos ocupa. ${ }^{7}$

Dado que la fecha de confección del códice se ha estimado en la segunda mitad del siglo XIII, y no hay otra referencia sobre los poseedores anteriores del documento ni de aquellos que lo confeccionaron, es necesario buscar otros indicios que nos puedan proporcionar pistas al respecto. Una información inicial la ofrecen los calendarios presentes en el códice. En el localizado entre los folios $19 \mathrm{r}-21 \mathrm{v}$, se señala

5 GONZÁLVEZ RUIZ, 2005: 148.

6 Véase BELTRÁN DE HEREDIA, 1970: 421 ss.

7 GONZÁLVEZ RUIZ, 2005: 148. 
la celebración de fiestas para diecisiete obispos de diversas ciudades francesas (Alet, Angers, Bourges, Besançon, Burdeos, Embrun, Langres, Limoges, Noblat, Poitiers, Salency, Tours y Valence), de los cuales la mitad se adscribe a ciudades de departamentos del centro-oeste de Francia, apuntándose así a un hipotético origen francés del manuscrito.

\section{PAUTADO MUSICAL Y DISPOSICIÓN DE LAS VOCES}

La disposición de los pentagramas presenta dos tipos diferenciados, tanto por el número de líneas como por el tamaño de la caja de escritura. Por un lado, la primera pieza, el conductus monofónico Ave gloriosa virginum regina se dispone en una caja de $85 \times 115 \mathrm{~mm}$ y ocho pautados en pentagrama por folio, excepto algún fragmento en tetragrama (folios 230r al 231r, más dos pautados finales en el 231v). El resto del manuscrito presenta una caja de escritura menor, de 70x102 mm y seis pautados por folio (excepto siete en el último), todos en pentagrama excepto el primero de los folios 234v, 236r y 238v, que son hexagramas (aunque la sexta línea no sea aprovechada en ningún caso), y el último del folio 238v, en el que el tenor del hoquetus In seculum se copia sobre tetragrama. El séptimo y último pentagrama del folio 239r está vacío.

Las líneas de todos los pautados, en tinta roja, están espaciadas de manera bastante uniforme, pero se evidencia que no ha sido utilizado un rastrum, ${ }^{8}$ no sólo a causa de las divergencias de distancias entre líneas, sino por diferentes ángulos de inclinación de éstas en un mismo pautado. Destacan los finales relativamente limpios en la mitad de las piezas (excepto en el conductus monofónico inicial, y en las dos últimas), con pautados que se extienden únicamente hasta donde alcanza la música, lo que revela la previsión con que se realizó la preparación del manuscrito. Previsión que no parece alcanzar al caso del hoquetus final, el cual quizás se realizó de manera posterior al resto de piezas, sobre un pautado preparado a priori sin el conocimiento exacto de cuál podía ser la extensión final de la pieza. No se utilizan custos en el manuscrito, excepto al final de la línea del tenor en el folio 234r, para girar al siguiente folio. Señalemos que la ausencia de custos es un rasgo común en la polifonía parisina desde el final del siglo XII hasta el final del XIV. ${ }^{9}$

Las piezas polifónicas muestran las voces separadas en páginas enfrentadas (verso contra recto) y tenor en la parte inferior, a excepción del conductus $O$ lilium convallium (E-Tc 98.28 - 5) y el hoquetus In seculum final, ambos a tres voces en partitura. Los cambios de página funcionan perfectamente para sincronizar todas las voces, lo cual posibilita el uso práctico del documento en la práctica musical. Las notas se distribuyen con regularidad y comodidad de lectura, siendo el único caso de escasez de espacio

8 El uso de rastrum no es común hasta después de mediados del siglo XIV, siendo habitual trazar las líneas individualmente, como en Huelgas o el manuscrito de Madrid. No obstante, se citan ejemplos del posible uso de un rastrum a partir de 1300 . Véase BELL, 2003: 27, nota. HAINES, 2008: 366.

9 HUGLO, 1991: 33. El autor comenta asimismo la prescripción del Anónimo IV respecto al uso de custos únicamente para los tenores, y la tipología de diferentes símbolos usados para esta función. 
el tenor de Ave Gloriosa / Domino (E-Tc 98.28 - 4), el cual aparece comprimido pero perfectamente encajado y legible en la línea.

Todas las voces se presentan en claves de Do, excepto el tenor Domino (E-Tc 98.28 - 4), en clave de Fa. En cuanto a armaduras, únicamente se usa un bemol ( $\mathrm{Si}$ ) para el tenor Agmina y un sostenido (Fa) para el triplum de $O$ lilum convallium. El uso de alteraciones accidentales escritas se limita a un par de Sib en el triplum de Agmina milicie (E-Tc 98.28 - 2), y otro Si bemol en el duplum de Ave gloriosa mater salvatoris (E-Tc 98.28 - 4). La ficta se puede limitar a unos muy escasos bemoles además de algún Do\# en $O$ lilium convallium (E-Tc 98.28 - 5) y en In seculum (E-Tc 98.28 - 6).

\section{CAPITALES Y TEXTO}

El conductus monofónico inicial presenta una capital de tamaño menor que las del resto de piezas, de color azul con filigranas rojas descendentes, las cuales abarcan solo tres pentagramas hasta un tercio aproximadamente de la caja. A lo largo del resto de esta pieza, cada estrofa se inicia con una pequeña capital, alternativamente roja y azul. En el resto de piezas las iniciales capitales, mayores que la anterior y presentes al principio de cada voz cum littera (roja con filigrana azul para el duplum, azul con filigrana roja para el triplum), ostentan una larga filigrana vertical que abarca la totalidad de pentagramas, sobrepasando el final de la caja. La excepción es el hoquetus final, sine littera, en el cual no hay capital inicial, sino tan solo las palabras In seculum bajo el tenor, en negro y con letra ligeramente más alta que el resto de textos generales. Los tenores vienen señalados al principio de la pieza, con una pequeña capital pero en negro. El conductus polifónico, O lilium convallium (E-Tc 98.28 - 5) ostenta una gran capital azul alargada con filigrana roja que abarca las tres voces, dispuestas estas en partitura.

La combinación de color rojo y azul usada en estas iniciales es característica de los manuscritos copiados en París. ${ }^{10}$ La decoración de las filigranas también muestra características típicamente francesas: las "horquillas" superiores que se doblan hacia la izquierda en los extremos superiores de las filigranas, y los tallos que se extienden hacia abajo, finalizando en dos zarcillos curvados y enfrentados (tres en el caso del conductus realizado en partitura $O$ lilium convallium). No obstante, estos caracteres son demasiado comunes en los manuscritos europeos de la época como para ser indicativos determinantes de la procedencia. En cambio, la escritura del texto, en letra gótica también de tipo común en el momento, muestra ciertos indicios como la forma de abreviar la palabra "et", o la ejecución de ciertas palabras, como la que cierra el folio 235v, "gaudia", que se relacionan con escrituras al norte de los Pirineos. ${ }^{11}$

10 NORWOOD, 1990: 496. También EVERIST, 1981: 54. Al respecto de los talleres parisinos, BRANNER, 1966: 65-67.

11 Agradezco estas observaciones al profesor Jesús Alturo, de la Universitat Autònoma de Barcelona, quien amablemente inspeccionó la escritura del documento. 


\section{EL REPERTORIO}

El manuscrito contiene un conductus monofónico, dos motetes a tres voces (uno de ellos con texto no descrito hasta ahora, en el duplum), un motete a dos voces, un conductus a tres voces (del cual constituye la cuarta copia conocida, incluyendo la contenida en el códice de Florencia, la gran colección de conductus de Notre Dame) $)^{12}$ y un hoquetus a tres voces sin texto. Este conjunto de piezas concuerda con el repertorio de Notre Dame típico en las fuentes españolas, en las cuales predominan conductus y motetes frente a los organa, más abundantes en proporción en el resto de fuentes principales de esta Escuela, quizás por una adopción algo tardía del repertorio. No obstante, es muy significativo que las tres piezas con texto concordantes con fuentes españolas ( $E$ - Tc 98.28 - 2, 3 y 4) lo hagan únicamente con una fuente principal como es el códice de Las Huelgas, siendo por lo demás concordancias comunes en las fuentes europeas, incluyendo las principales (Florencia, La Clayette, Bamberg, o Montpellier). Por tanto, el repertorio de $E-T c 98.28$ se presenta como una selección de piezas en sí mismas ajenas a una posible tradición específicamente peninsular, aunque con una ordenación similar a la de las principales fuentes ibéricas de polifonía antigua, los códices de Las Huelgas y Madrid. Comienza con una secuencia (conductus en este caso) monofónica; sigue con una sección central en la que se mezclan indiscriminadamente motetes y conductus polifónicos, como sucede en los manuscritos ibéricos, ${ }^{13}$ y finaliza con el hoquetus como pieza no relacionada con el resto del repertorio, quizás fuera de la planificación inicial. Teniendo en cuenta que los motetes dobles de $E-T c 98.28$ concuerdan en forma de conductus-motete en la mayoría de otras fuentes, se comprueba que, de las seis piezas de E-Tc 98.28, cuatro se relacionan con el género de conductus, asociado a la zona sur de Francia donde se admite en general que el género evolucionó. ${ }^{14}$

Las cinco piezas de E-Tc 98.28 cum littera son de temática mariana. Esto no es extraño en el repertorio asociado a la Escuela de Notre Dame, generado en unos años en que los estamentos eclesiásticos potenciaban la idea de la Virgen María como Madre de Dios, y como el mejor camino para la salvación del pecador. ${ }^{15}$ En la música de esta Escuela, los textos dedicados a la Virgen María se originan como un fenómeno latino, y muestran un importante aumento en la producción en el siglo XIII, especialmente en forma de motetes piadosos con textos en francés. ${ }^{16} \mathrm{El}$ importante y central culto de la Virgen, con el impacto que tuvo en las diversas manifestaciones artísticas de esta época, se relaciona no solamente con la identificación de la figura de María con la propia Iglesia, sino con la necesidad de reafirmar los dogmas fundamentales católicos frente a las herejías del momento: la Madre de Dios es la prueba irrefutable de la Encarnación de Cristo entre los humanos, y su historia el apoyo necesario de la teología basada en los 2010).

12 KNAPP, Janet, "Conductus, 2. Notre Dame of Paris", en www.oxfordmusiconline.com (acceso el 16 de Mayo de

13 BELL, 2003: 68.

14 GILLINGHAM, 1991: 59.

15 BALTZER, 2007: 122. También, GILLINGHAM, 1980: 53 para el caso de las secuencias marianas, género especialmente predilecto en el ambiente cisterciense, según afirma el autor.

16 EVERIST, 2004: 130. 
textos de San Dionisio, dominantes en el pensamiento del abad Suger de Saint Denis y base de un arte gótico de profundo significado teológico. ${ }^{17}$

Un repertorio polifónico como el de E-Tc 98.28, compuesto por conducti y motetes, sólo es adecuado para su uso en un servicio cuando pone música a textos litúrgicos. No siendo así, su uso se restringiría al canto privado en capillas y oratorios de los canónigos..$^{18}$ De hecho, una ordenación litúrgica de motetes sólo se constata en los primeros fascículos de I-FI 29.1, y se abandona en favor de una ordenación alfabética en fascículos y fuentes posteriores. En el caso de $E$-Tc 98.28 precisamente es así, pues observamos la ordenación de los motetes por orden alfabético de los tenores: Agmina - Alleluia - Domino - In seculum. A pesar del escaso número de piezas, el dato es significativo, y además apunta a una voluntad de copia de esta parte del repertorio. Es importante destacar que el último folio con música, el 239r, ofrece un aspecto de trabajo inacabado, todavía con las líneas de guía dibujadas. Esto incita a creer que la música conservada en el manuscrito de Toledo no es sino el inicio de un proyecto de copia más amplio, que quedó interrumpido en el hoquetus. ${ }^{19}$

El contenido de este manuscrito de Toledo y las concordancias de todas las piezas se muestran en la Tabla 1.

Tabla I. Contenido de E-Tc 98.28.

\begin{tabular}{|c|c|c|c|c|c|}
\hline $\mathrm{N}^{\mathrm{o}}$ & Folios & Incipit & Tipo & Voces & Concordancias \\
\hline 1 & $230 r-231 v$ & $\begin{array}{l}\text { Ave gloriosa } \\
\text { virginum regina }\end{array}$ & Conductus & 1 & $\begin{array}{l}\text { GB-Lbl Royal } 7 \text { A.vi.- } G B-L b l \text { 2615-f. 3.- } \\
I-F I \text { 29.1, f. } 447 .-F-P n \text { 24541-f. XX.- GB- } \\
\text { Lbl 978-f. 3-7. }\end{array}$ \\
\hline 2 & $232 v-234 v$ & $\begin{array}{l}\text { Agmina malicie / } \\
\text { Agmina milicie / } \\
\text { Agmina. }\end{array}$ & $\begin{array}{l}\text { Motete } \\
\text { doble }\end{array}$ & 3 & $\begin{array}{l}D \text {-BAs } 115,6 \text { (motete a } 3 \text { v.).- F-Pn } 13521 \text {, } \\
22 \text { (motete a } 4 \text { v. De la Virge Katerine } \\
\text { Chantera / Quant Froidure trait a fin / } \\
\text { Agmina milicie / Agmina).- GB-Ctc 0.2.1, } \\
10 \text { (conductus-motete a } 3 \text { v.).- I-FI 29.1, } \\
835 \text { (conductus-motete a } 3 \text { v. sin texto en } \\
\text { triplum).- E-BUlh, } 89 \text { (motete-conductus a } \\
3 \text { v.).- GB-Lbl } 2615,17 \text { (conductus-motete } \\
\text { a } 3 \text { v.).- GB-Lbl } 274,4 \text { (conductus-motete } \\
\text { a } 2 \text { v.).- F-Pn } 15139,1,3 \text { (motete a } 2 \text { v.).- } \\
D-W 1099,87 \text { (motete a } 3 \text { v. sin texto en } \\
\text { triplum). }\end{array}$ \\
\hline
\end{tabular}

17 Al respecto véase por ejemplo DUBY, 2005: 156 y ss. También PAUL, 2003: 366 y ss.

18 WRIGHT, 1989: 32. RICO, 2005: 260.

19 Por la peculiar escritura del hoquetus y el uso de una tinta sutilmente diferente, se puede suponer que la copia se detuvo en la quinta pieza, siguió más adelante con el hoquetus, y al acabar este se abandonó definitivamente. 


\begin{tabular}{|c|c|c|c|c|c|}
\hline 3 & $234 v-236 r$ & $\begin{array}{l}\text { Res nova } \\
\text { mirabilis / Virgo } \\
\text { decus castitatis / } \\
\text { Alleluya }\end{array}$ & $\begin{array}{l}\text { Motete } \\
\text { doble }\end{array}$ & 3 & $\begin{array}{l}\text { F-Pa 3517-18, 1.- D-BAs 115, 95.- F-BSM } \\
148,6 \text { (motete a } 2 \text { v. Virgo /Alleluya).- F-Pn } \\
13521,12 .- \text { GB-Ctc 0.2.1, } 9 \text { (conductus- } \\
\text { motete a } 3 \text { v.).- E-BUlh, 107.- GB-Lbl } \\
30091,9 \text { (motete a } 2 \text { v. Virgo / Alleluya).- } \\
\text { GB-Ob 72, 5, (motete a } 2 \text { v. Virgo } \\
\text { Alleluya).- F-Mo 196, 58.- D-Mbs 16444, } \\
11 .\end{array}$ \\
\hline 4 & $236 v-237 r$ & $\begin{array}{l}\text { Ave gloriosa } \\
\text { mater salvatoris } \\
\text { / Domino }\end{array}$ & Motete & 2 & 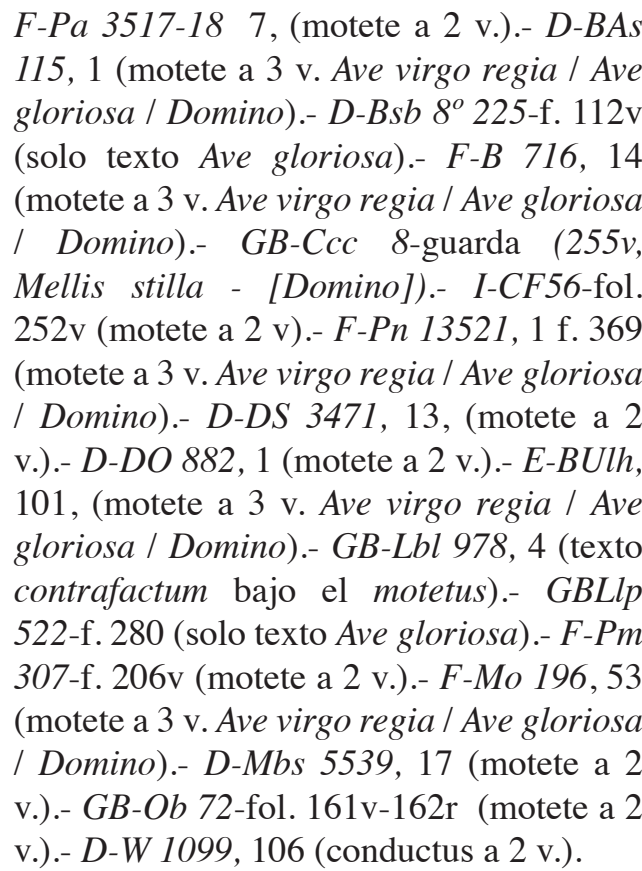 \\
\hline 5 & $237 v-238 v$ & $\begin{array}{l}\text { O lilium } \\
\text { convallium }\end{array}$ & Conductus & 3 & $\begin{array}{l}\text { I-CF56-fol. 252-252v.- I-FI 29.1, 672.- } \\
\text { D-Sl 95-f. } 76 \text { (conductus a } 2 \text { v.). }\end{array}$ \\
\hline 6 & $238 v-239 r$ & In seculum & Hoquetus & 3 & $\begin{array}{l}D-B A s \text { 115, 104.- E-Mn 20486, 71.- F-Mo } \\
\text { 196, } 73 .\end{array}$ \\
\hline
\end{tabular}

E-Tc 98.28 - 1. Ave gloriosa virginum regina (f. 230r-231v). Conductus monofónico sobre texto de Philippe le Chancelier (ca.1160 - ¿1236?), en forma de secuencia o lai. ${ }^{20}$ Sobre el sistema de repetición doble de melodías cambiantes, con un intrincado y sofisticado uso de la variación melódica, destaca la presencia de una fórmula recurrente que cierra cada frase (Ejemplo 1):

20 ANDERSON, 1972: 364. Sobre el lai sacro, véase EVERIST, 2004: 130. 


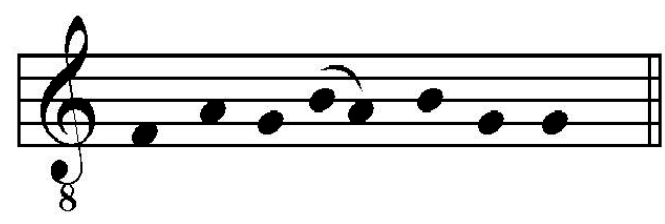

Ejemplo 1. Motivo en E-Tc $98.28-1$

La música concuerda con la del Lai de la Pastourelle y el Lai des Hermins, ${ }^{21}$ por lo que se trata de un contrafactum de estas o de un modelo anterior común, aceptando la preeminencia de melodías profanas que se "sacralizan" con un texto nuevo. Esta adaptación de melodías preexistentes no es práctica extraña al repertorio asociado a Notre Dame en las fuentes ibéricas, como se comprueba ya en los conductus del manuscrito de Madrid. ${ }^{22}$ Los propios teóricos de la época, como el caso de Franco de Colonia, o Walter Odington, corroboran que el procedimiento adecuado para componer un conductus es utilizar una melodía pulchriorum quam potest, ya sea cognitis vel inventis. ${ }^{23}$

El ritmo de esta pieza no queda determinado en la escritura, ni en E-Tc 98.28 ni en la versión de Florencia, debido a la disposición silábica, sin ligaduras que clarifiquen el uso de posibles modos rítmicos. En ausencia de las caudae propias de algunos conductus polifónicos que ayudan a deducir un modo rítmico concreto, ${ }^{24}$ se puede compensar en este caso considerando las versiones de $G B$ - Lbl 2615 o GB-Lbl 978 , las cuales evidencian el uso del primer modo rítmico, constituyendo algunas de las escasas versiones mensurales conservadas de conductus monofónicos. ${ }^{25}$ Este primer modo rítmico es, junto con el segundo, uno de los dos preferidos para la interpretación mensural de las secuencias ${ }^{26}$ El modo melódico es de Sol, como la mayoría de los conductus monofónicos de Florencia. ${ }^{27}$

E-Tc 98.28 - 2. Agmina malicie / Agmina milicie / Agmina (f. 232v-234v). Motete a 3 voces. Esta es una versión nueva, pues presenta un texto hasta ahora desconocido, Agmina malicie, de autor anónimo. Dice así: ${ }^{28}$

Agmina malicie sunt multipharia, et gentis nepharie patet versucia.

Plantula iusticie parit zizannia, florent ficus fatue fructus est palea.

Ierusalem filie sunt in tristicia, omnes sunt Martha nullus Maria.

21 JEANROY, et alt., 1901. Son los números XXIV y XXVII, respectivamente.

22 Ejemplos en ASENSIO, 2002: 83-96.

23 ELLINWOOD, 1941: 178-179. En general, también para el caso de los motetes piadosos constituye un procedimiento común, que genera complejos de piezas con textos variables. Véase EVERIST, 2004: 140 ss.

24 Al respecto, PARRISH, 1978: 93 y ss; asímismo, EVERIST, 2000: 138 ss. También STEINER, 1966: 65-66.

25 STEINER, 1966: 62-63. Véase también HAGGH, y HUGLO, 2004: 206. Respecto al uso de versiones mensurales para transcribir repertorio paralelo véase ANDERSON, 1973: 288-304 y ANDERSON, 1978: 480-489.

26 Según GILLINGHAM, 1980: 55.

27 STEINER, 1966: 69.

28 Agradezco nuevamente al profesor Jesús Alturo, así como al profesor José Martínez Gázquez, ambos de la Universitat Autònoma de Barcelona, su asistencia en la transcripción y traducción de este texto. 
Rachel flores cotidie mutatur in lya, Syon mater glorie in Babilonia.

Lex iusticie in nequicia, omnes querunt munera ecclesie,

venundantur et emuntur, pecunie stant pro sciencia.

Magna premia sunt memorie, cadit theologia nil prodest hodie.

Radix avaricie patet symonia, divitis nequicie pauperis sunt naufragia. ${ }^{29}$

El nuevo texto constituye una crítica a la situación espiritual de la sociedad del momento, con abundantes metáforas derivadas de pasajes de la Biblia, en las que destacan el uso de términos botánicos (ficus, flores, plantula, radix, zizannia). Se añade al duplum del motete en contraste con el texto del triplum, el ya conocido Agmina milicie, en honor de la Virgen y Santa Catalina de Alejandría, cuya devoción tuvo especial auge en la época de las cruzadas, en los siglos XII y XIII. De hecho, en París era patrona de los escolares y los estudiantes de teología. La contraposición entre los conceptos de malitia y militia tiene su origen en el establecimiento de la Paz o Tregua de Dios a comienzos del siglo XI, pero se concreta en los escritos de Bernard de Clairvaux (1090-1153), especialmente en su De laude novae militiae. En este tratado, San Bernardo (uno de los santos cuya conmemoración se incorporó a los ritos de la catedral parisina en el siglo XIII ${ }^{30}$ distinguía entre la nueva orden de caballeros-monjes, los Templarios, que sería la auténtica militia, del resto de caballeros, a quienes se les asigna la peyorativa característica de malitia. ${ }^{31}$ Todo ello en una situación de defensa de las cruzadas contra los infieles (ya fuera en España o en Tierra Santa), y como metáfora más amplia de división en la sociedad de caballeros. El autor de este nuevo texto podría por ello ser relacionado con en el ambiente cisterciense en el que se cultivaron las ideas de Bernard de Clairvaux, a partir de la segunda mitad del siglo XII.

La versión de Toledo se suma así un complejo de piezas concordantes, en el que la forma más común es la de conductus-motete a 3 voces, sobre el texto de Agmina milicie celestis, texto probablemente de Philippe le Chancelier, ${ }^{32}$ un autor con decenas de poemas musicados en el repertorio de Notre Dame en forma de conductus y motetes. ${ }^{33}$ La música proviene de la cláusula Agmina de F-Pn $15139, \mathrm{n}^{\circ} 40 .{ }^{34}$ En $D-W 1099$ figura con la incripción "De Sancta Katharina". ${ }^{35}$ La melodía de Agmina celestis se encuentra en versión monofónica en el Manuscript du Roi ${ }^{36}$ f. 199, con un texto contrafactum en occitano, L'altrier

29 "Los ejércitos de la maldad son de todo tipo, y los pueblos se exponen a la impiedad y la malicia. La plántula de la justicia engendra falsas doctrinas, florecen fallidas las higueras, paja es el fruto. Las hijas de Jerusalén están afligidas, todas son Marta, ninguna María. Cada día las flores de Raquel se trocan en las de Lía, Sion, madre de la gloria [se troca] en Babilonia. La ley de la justicia, en depravación, todos buscan favores de la Iglesia, se venden y se compran, las riquezas se anteponen al conocimiento. Hay grandes recompensas para la memoria, cae la teología, hoy nada sirve. La raíz de la avaricia expone la simonía, las perversidades del rico son la perdición del pobre."

30 Concretamente se instauró su celebración el 25 de agosto desde de 1207. Véase WRIGHT, 1989: 72-73.

31 Véase GRABOIS, 1992. Sobre el pensamiento de San Bernardo, PAUL, 2003: 260 y ss.

32 Higini Anglés, siguiendo la confusión común del momento, hoy resuelta, en El Códex Musical de las Huelgas (p. 247) cita el autor como Philippe de Grève, canónigo de Notre Dame $(\dagger 1220)$ del cual no sobrevive ningún escrito. Véase RILLONMARNE, 2008: 6 y 34. También C. WRIGHT, 1989: 294 y ss. El texto de esta pieza en Analecta Hymnica Medii Aevi, 21, (en adelante, AH): 195 .

33 Una lista y discusión sobre este conjunto de obras en PAYNE, 1986: 234 y ss.

34 Bibliothèque Nationale de France, lat. 15139 (f. 292v).

35 Santa Catalina de Alejandría, festividad el 25 de noviembre.

36 Facsímiles de la pieza de $F-P n 814$ y $F$-Pn 15139 en AUBREY, 1997: 20-21. La autora argumenta que esta versión monódica se realizó a partir de una versión preexistente polifónica a la que se adaptó el nuevo texto. 
cuidai aber druda, que se ha considerado escrito por un poeta francés del norte; quizás se trate de la versión original de la música. Aquí se narra el desencanto por el amor terrenal, que se transforma en la versión dedicada a Santa Catalina en una alabanza al amor espiritual; se superpone al registro erótico de Quant froidure trait a fin en la versión a cuatro voces de La Clayette. Es otro ejemplo de intertextualidad, que en menor medida se da en los dos textos de la versión de Toledo, ${ }^{37}$ aunque se observa un esfuerzo por parte del poeta de hacer coincidir la rima de los versos y las sonoridades de los finales de frase. Agmina malicie se habría compuesto en una época en la que el motete ya había evolucionado desde su origen latino, sacro y en ocasiones litúrgico, hasta formas en las que la politextualidad da paso cada vez más a la utilización del francés, las temáticas se alejan de temas sacros, y la intertextualidad se refleja en sofisticados juegos metafóricos y contrastes de términos y expresiones. Por ello, el autor de este poema, escrito en latín en una época tardía ${ }^{38}$ y denunciando los males espirituales de la sociedad del momento, puede ser ubicado en el ambiente monástico, y especialmente cisterciense por la afinidad temática y terminológica. Un texto tanto de denuncia como de intención moralizadora.

A nivel musical, en todas las versiones polifónicas que usan estas mismas melodías se ha constatado una equivalencia casi absoluta en la notación musical entre las diversas fuentes, al nivel incluso de neuma a neuma. ${ }^{39}$ Pero un rasgo diferencia dos grupos de versiones: aquellas que acaban las frases musicales con dobles notas repetidas ( $F-M o 196, F-P n 15139, G B-L b l 274)$ y aquellas que en cambio reducen estos finales a una nota simple (Huelgas, Bamberg, GB-Lbl 2615, La Clayette y en nuestro caso E-Tc 98.28). El tenor de nuestro motete procede del melisma "Agmina" que pertenece al sexto responsorio de la fiesta de Santa Caterina, Virgo. Sponsus.

E-Tc 98.28 - 3. Res nova mirabilis / Virgo decus castitatis / Alleluya (f. 234v-236r). Motete mariano a 3 voces no basado en ninguna cláusula previa, ${ }^{40}$ y con tenor de origen desconocido. Representa uno de los primeros ejemplos conservados de motete en latín de nueva composición. ${ }^{41}$ Res Nova mirabilis es texto atribuído al compositor de secuencias parisino y precentor de la Catedral de Notre Dame, Adam de St. Victor († 1146), con la indicación "Pour les fêtes de le Sainte Vierge". ${ }^{2}$ Virgo decus castitatis es texto de autor anónimo.

Destaca la diferencia en longitud de los versos de los diferentes textos, lo que conlleva que las voces no cadencien juntas casi en ningún momento. Este factor, característico del motete de mediado el siglo XIII ${ }^{43}$ implica que las frases musicales completas y simultáneas, en cada voz, consten de diferente número de perfecciones. De hecho, la concordancia se limita a la presencia de las notas largas del primer modo

37 Véase un comentario detallado en HUOT, 1997: 50 y ss. También SCHRADE, 1955: 400 y ss.

38 La datación tardía invita a calificar este manuscrito como "copia terminal" en el repertorio asociado a la Escuela de Notre Dame, siguiendo el término acuñado por Mark EVERIST, 1981: 60.

39 Véase AUBREY, 1997: 19 y ss.

40 Véase PESCE, 1987: 421, nota. También ANDERSON, 1970: 109-128.

41 ANDERSON, 1969: 178. 345-374.

42 GAUTIER, 1894: 356; también AH 46: 193. Sobre este autor véase FASSLER, 1984: 233-269; y FASSLER, 1987:

43 EVERIST, 2004: 177. 
rítmico, que sí son coincidentes. ${ }^{44}$ Es posible suponer que los textos simultáneos resulten difíciles de entender debido a estas discordancias, y también a causa de la densidad rítmica que muestran las voces. ${ }^{45}$

E-Tc 98.28 - 4. Ave gloriosa mater salvatoris / Domino (f. 236v-237r). Motete mariano a dos voces (AH 20,p. 184), es la pieza con mayor número de concordancias de las que se encuentran en este manuscrito, siendo esta versión a dos voces la más común. Tanto la versión de Huelgas como de Bamberg, en cambio, vienen a tres voces, pues se les añade como triplum, Salve [Ave], virgo regia. El tenor proviene del Benedicamus Domino para las primeras Vísperas "In festis Solemnibus". ${ }^{46}$ Los tenores en Huelgas, GB-Lbl 978 y Bamberg se presentan en notas simples, mientras que el copista de la versión de Toledo ha optado por ligaduras de tres notas, igual que las usadas en Montpellier.

E-Tc 98.28 - 5. O lilium convallium (f. 237v-238v). Conductus mariano únicamente concordante con I-CF 56, I-FI 29.1 y D-Sl 95. En Toledo viene a tres voces, como en I-FI 29.1. La versión de D-Sl 95 es a dos voces (las dos inferiores de $I-F I 29.1$ y E-Tc 98.28) y se presenta escrita en partes separadas, no en partitura.$^{47}$ La disposición de voces en Toledo concuerda plenamente con la de I-FI 29.1, pero se distingue en la realización de ligaduras y en la diferenciación de longas, especificándose claramente el uso del segundo modo rítmico (un modo poco común en los conductus parisinos). ${ }^{48} \mathrm{Tal}$ como propone Sarah Fuller, ${ }^{49}$ la versión a dos voces de Stuttgart, por su coincidencia con el resto del repertorio aquitano, podría ser anterior a la parisina de I-FI 29.1. En E-TC 98.28 al igual que en I-FI 29.1, la voz superior se diferencia rítmica y estilísticamente de las dos inferiores, las cuales muestran ciertos caracteres propios de la polifonía aquitana: movimiento contrario de voces en motivos melódicos de tercera, preferencia por las terceras simultáneas o intercambio de voces. Esto podría señalar que la voz superior es añadido posterior a una versión primitiva a dos voces.

\section{EL HOQUETUS IN SECULUM}

E-Tc 98.28 - 6. In seculum (f. 238v-239r). La aparición de una nueva versión del hoquetus In seculum reviste especial interés por la atribución de un posible origen hispánico del mismo sugerido en la cita que hace el Anónimo IV, autor que se supone activo el último cuarto del s. XIII. ${ }^{50}$ En el capítulo titulado De pausationibus de su tratado menciona "le hoket Gallice, quod quidam Hyspanus fecerat et cetera". ${ }^{51}$ Precisamente en

44 La música de Virgo decus castitatis junto con el tenor Alleluya se usa como ejemplo en el tratado Discantus possitio vulgaris precisamente destacando esta coincidencia de longas, pero igualmente señalando la posibilidad de ejecutar "ad placitum" los silencios en los que descasen las tres voces simultáneamente. Véase al respecto PAGE, 1988: 147-164. El texto del tratado se puede consultar en KNAPP, 1962: 200-215.

45 Véanse otras reflexiones al respecto en PESCE, 1986: 95.

46 Antiphonale Sacrosanctae Romamae Ecclesiae pro diurnis horis, Roma: Typis Polyglottis Vaticanis, 1912, p. 48*.

47 Véase TREITLER, 1964: 39.

48 KNAPP, 1990: 629. Se asocia el segundo modo rítmico a los textos en lengua francesa, y por tanto al motete bilingüe.

49 FULLER, 1971: 185.

50 El texto del Anónimo IV se data actualmente como posterior a 1280. Véase FASSLER, 1987: 350. Al respecto de un posible origen de la técnica de hoquetus en una práctica improvisada anterior, véase DALGLISH, 1978: 3-20. En cualquier caso, el interés de la cita del Anónimo IV se centra en rastrear el origen de una versión concreta de hoquetus, la que se basa en el tenor In Seculum. Sobre la cuestión del origen español del repertorio creado en estos siglos, véase VEGA CERNUDA, $1990: 423$.

51 Traducido al inglés en YUDKIN, 1985: 54. Edición del original latino en RECKOW, 1967: 61. 
el códice de Madrid (número 71) se conserva una versión de este hoquetus, considerado una de las primeras obras del género, si no la primera. ${ }^{52}$ La versión de Toledo concuerda musicalmente con la de Madrid, así como con dos fuentes más (Montpellier 73, Bamberg 104). Corresponde al tipo denominado In seculum longum, por presentar el tenor en quinto modo rítmico, es decir, series de longas perfectas, y por contraste con la versión denominada en el códice de Bamberg In seculum breve (Bamberg 106). En ésta el tenor, por disminución rítmica, ha pasado del quinto al segundo modo rítmico, con lo que se constituye en una sucesión de series de breves y longas imperfeccionadas, resultando en consecuencia más corta la pieza. Hay también tres versiones del hoquetus en Montpellier, una como motete doble (Montpellier 137) con los textos Ja n'amerai y Sire Dieus, y tenor "largo", otra a cuatro voces por el añadido del triplum Ja n'amerai (Montpellier 2), también sobre el tenor en quinto modo, y la tercera con la misma configuración a cuatro voces pero sobre la citada versión In seculum breve (Montpellier 3). A estas cuatro se suma una quinta y notable versión cual es el "doble hoquetus" a cuatro voces emparejadas, hallado en un bifolio de la Biblioteca Universitaria de Salzburg. ${ }^{53}$

Como se ha indicado, el hoquetus de Toledo copia las tres voces en partitura, a diferencia de la versión de Madrid, en la que el triplum se copia separado de duplum y tenor, ambos en partitura. Dado que este folio de Madrid (122v, cerrando el segundo cuaternión de la quinta sección del códice $)^{54}$ consta de ocho pautados, se ha propuesto que la tercera voz se copió separada, no necesariamente como un añadido posterior a una versión inicial de dos voces, sino de manera obligada ya que hubieran sido necesarios nueve pautados para copiar las tres voces juntas. ${ }^{55}$ Curiosamente, si se examina el siguiente folio de Madrid, el 123r, se observa que en este sí hay nueve pautados, quedando el noveno desaprovechado, ya que la pieza que contiene es el conductus a dos voces [P] arit preter morem.$^{56}$ Además, el propio folio $122 \mathrm{v}$, que contiene In seculum, podría haber albergado perfectamente nueve pautados, y así copiar las tres voces en partitura, como se verifica en E-Tc 98.28. No cuesta imaginar que el copista de Madrid copió el hoquetus en un espacio no previsto inicialmente para ello, al final de un fascículo en el que se habían copiado los ocho pentagramas de las piezas precedentes. La copia del hoquetus en Toledo ya estaba prevista a tres voces, y se ejecuta fácilmente en partitura usando los seis pentagramas por folio que se vienen utilizando en el manuscrito. Por tanto, la disposición a tres voces en partitura del hoquetus en Toledo, coincide con la versión de Bamberg, y difiere tanto de la de Madrid, ya discutida, como de la de Montpellier, en la cual las tres voces se copian separadas.

52 GÓMEZ MUNTANÉ, 2009: 215. Se discute la versión de Madrid en ASENSIO, 1998: 13-28.

53 Sería el único superviviente de los llamados "hoketos contraduplices", citados por Jacobus Leodiensis (de Lieja) en su Speculum musicae. Véase JEFFERY, 1984: 1-48. Otros hoqueti recientemente recuperados se describen en WOLINSKI y HAGGH, 2010: 43-58. Sobre las versiones de In seculum concordantes con el de Madrid, GÓMEZ MUNTANÉ, 2009: 215. También ASENSIO, 1998: 22.

54 La división en secciones, esquematizada en GÓMEZ MUNTANÉ, 2009: 210-211.

55 ASENSIO, 1998: 17.

56 La inicial $P$, que indicamos entre corchetes, está ausente del manuscrito: no se llegó a dibujar, pero el sangrado de dos pentagramas sí está presente. ¿Por qué con previsión se sangraron dos pentagramas para el conductus a dos voces, y luego se llenó el folio con nueve pentagramas, número impar? Por supuesto, podría haberse usado el noveno pentagrama para un tenor de un posible motete o motete conductus a tres voces. Quizás sobre las mismas voces de Parit preter morem. Para más misterio, el folio siguiente de Madrid, 123v, retoma la disposición a ocho pentagramas. Al ser vuelta de folio, se invalida la posibilidad de una versión a tres voces de esta pieza. 
En lo referente al contenido musical, el hoquetus de Toledo presenta máxima equivalencia melódica en el duplum respecto a las demás concordancias, siendo especialmente fiel a la versión de Montpellier, incluso a nivel de ligadura a ligadura. En cambio, el triplum se diferencia notablemente del de la versión de Madrid, en la que faltan diversas notas que sí aparecen en Toledo, Montpellier y Bamberg. La ausencia de las dos notas Sol que faltan en Madrid al final de la primera línea del triplum (perfecciones 31 y 32) es achacable a un borrado accidental. Pero el Mi ausente en la perfección 48 de Madrid (presente en las demás concordancias) sería una variante melódica, como lo es el final de este triplum que añade un Do en la perfección 89 respecto a las otras versiones. Tampoco es exactamente idéntica la disposición de algunas ligaduras y la indicación de alguna propiedad entre los manuscritos de Toledo, Montpellier y Bamberg. En conclusión, el triplum de Toledo se corresponde más fielmente a las versiones de Montpellier y Bamberg que a la de Madrid. En cuanto al tenor In seculum, en Toledo la disposición en ligaduras del mismo es una copia exacta de la versión de Madrid y de Montpellier, y difiere de la versión de Bamberg, en la cual se presenta en longas simples.

Cabe finalmente hacer mención de la relación que ya apuntó Dalglish ${ }^{57}$ entre el origen de la técnica y género del hoquetus entre cantores de la orden cisterciense (como una probable fijación por escrito de una práctica improvisada), la cual se ha vuelto a señalar acerca del recientemente descrito hoquetus sobre el tenor Manere, igualmente asociado a este mismo contexto. ${ }^{58}$ También en el caso del manuscrito de Toledo se puede proponer una relación del documento con el entorno intelectual cisterciense, como se ha comentado anteriormente.

\section{LA NOTACIÓN MUSICAL}

El estudio comparado de los diversos aspectos musicales del manuscrito de Toledo respecto a las fuentes coetáneas europeas, se ha realizado prestando especial atención a las principales fuentes españolas relacionadas: el códice de Las Huelgas y el manuscrito de Madrid, por la relevancia que pueden tener para determinar el origen del manuscrito toledano y el significado de su presencia en la Península Ibérica.

Aspectos paleográficos. Se pueden distinguir dos manos principales en la ejecución de la notación musical:

Mano A. Del folio 230 al 231v. Copia el conductus monofónico inicial, Ave gloriosa virginum regina. Es una notación musical oblonga algo tosca, muy diferente del resto de la notación del manuscrito (Ilustración 2). Se caracteriza por unas cabezas de nota con perfiles redondeados, caudas proporcionalmente cortas, de medida similar o incluso menor que la altura de las cabezas, pero que llegan a sobresalir por el extremo superior de la cabeza de la nota.

57 DALGLISH, 1978: 10.

58 WOLINSKI y HAGGH, 2010: 53-54. 


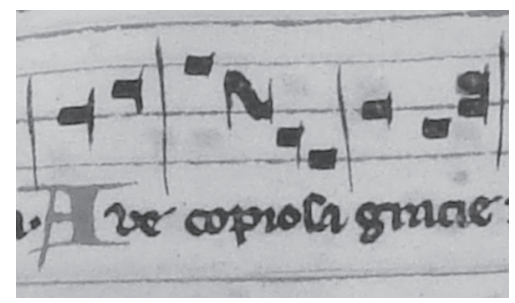

Ilustración 2. E-Tc 98.28 f. 230. Mano A

Las ligaduras binarias oblicuas presentan una característica curvatura en $S$ horizontal, mientras que las binarias regulares se ejecutan con excesos de caudas sobresaliendo por encima de la nota. Las conjuncturae presentan un aspecto poco uniforme. La clave de Do utilizada muestra un trazo diferente de las claves del resto del manuscrito. En conjunto es una notación que parece delatar cierta impericia o falta de hábito en la realización de la escritura musical. Su aspecto general recuerda a la "stroke notation", un tipo de notación musical sencilla destinada a personas habituadas a leer canto llano, pero no música mensural, que se usó en diversos países europeos a lo largo de los siglos XIV y XV.59 En cualquier caso, en Toledo sí hay diferenciación de longas y breves, a diferencia de manuscritos con notación similar como el de GB-Lbl Royal 7 A.vi (f. 127v). ${ }^{60}$

Mano B. La mano principal, del folio $232 \mathrm{v}$ hasta el 239r, ejecuta las piezas polifónicas. Se distingue por el dibujo preciso y estilizado de las longae, con largas caudas en proporción a las bien definidas y cuadradas cabezas de notas, claramente horizontales. Las caudas, dibujadas con ductus vertical casi perfecto, alcanzan en general el doble de longitud que las cabezas, e incluso un poco más. En general, en las piezas copiadas en el manuscrito de Madrid la proporción entre cabeza y cauda es mucho menor, y además las cabezas de nota se inclinan claramente. Por su parte, en Huelgas las caudas son más largas, inclinadas e irregulares en el trazo, menos rectilíneas que en Toledo (Ilustración 3).

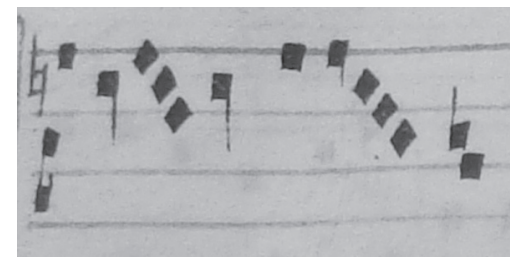

Ilustración 3. E-Tc 98.28 f.237v. Mano B

59 Ver al respecto BIEZEN y VELLEKOOP, 1984: 3-25. BENT, 1968: 137-156.

60 Facsímil de este folio en SANDON, 1982: 53, donde se observa la similitud del estilo de notación. 
Las diversas ligaduras, con o sin propiedad, o cum opposita propietate, son ejecutadas por esta mano con notable homogeneidad y claridad, así como las notas plicadas, que se distinguen perfectamente. Estas además presentan una forma cuadrada característica en su margen superior, sin la curvatura observable en muchas otras fuentes quizá coetáneas, como Huelgas o las diversas manos de Madrid. Las conjuncturae están dibujadas con gran regularidad. La precisión del copista no excluye algún error anecdótico, como algún detalle en las ligaduras que se comentará. Podemos afirmar que el copista era una persona experimentada en este trabajo. En la realización del hoquetus In seculum (folios 238v y 239r) se pueden apreciar ciertas diferencias de notación. Quizás sea el mismo copista que realiza el resto de la polifonía, escribiendo bajo otras condiciones, o con diferente material de escritura. Esta mano realiza las cabezas de notas ligeramente más amplias que la mano B, y las caudas algo más cortas, no llegando en ningún caso a alcanzar algo más que el equivalente de la altura de la cabeza, pero con una cierta tendencia a la inclinación vertical que no presenta la mano anterior (Ilustración 4). No obstante estas leves diferencias, esta mano es tan precisa y cuidadosa como la anterior.

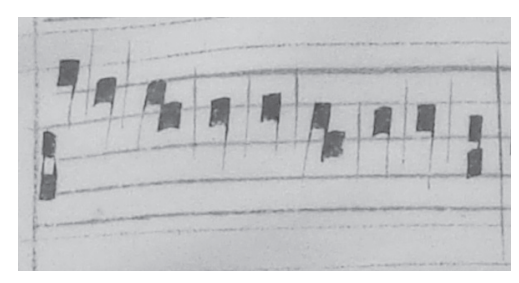

Ilustración 4. E-Tc 98.28 f. 239. Mano C

Aspectos musicales. Las fuentes que contienen el repertorio de la Escuela de Notre Dame evolucionan desde una notación rítmica de tipo modal hasta la aparición de una notación mensural, que retiene aspectos gráficos de la modal, pero asigna nuevas reglas de interpretación a las combinaciones de figuras simplicice y ligatae. Por supuesto, tal explicación lineal y evolutiva debe ser contrastable con las fuentes musicales, y con las fuentes teóricas de la época. Parece actualmente lo más acertado considerar que la evolución progresiva desde la notación modal hasta la mensural, que se expresaría paralelamente en la evolución de la música de la Escuela de Notre Dame hasta el Ars Nova, pasando por el Ars Antiqua, no debe haber sido en absoluto un proceso unidireccional y lineal, sino que sin duda debe responder a un escenario mucho más complejo. Las prácticas notacionales fueron coetáneas, conviviendo repertorios antiguos y modernos, notados según convenciones antiguas y modernas, en un mismo intervalo temporal e incluso geográfico. ${ }^{61}$ Por ello, la evolución de la notación en esta época es más bien similar a un árbol cuyas ramificaciones son prácticas diversas, relacionadas con tradiciones locales o con la formación de los escribas, cuyo acceso a las fuentes teóricas puede haber sido restringido, y cuya formación

61 BELL, 2003: 84. 
en los fundamentos teóricos de la notación pudo ser bajo, sesgado, o incluso nulo, si el copista realiza el trabajo de manera meramente automática. La inconsistencia entre las explicaciones teóricas y las realizaciones prácticas encontradas en las fuentes se revela al considerar que únicamente una fuente de tamaño considerable, Bamberg, respeta un único sistema coherente de notación en todo el manuscrito. ${ }^{62}$ Por tanto, cada fuente musical de este periodo debe ser considerada de manera individual, en el contexto de la producción, pero admitiendo un margen siempre posible de variación única y propia de la fuente en cuestión.

En el caso de Toledo, esta individualidad se refleja en primer lugar en la pieza inicial del manuscrito, el conductus monofónico Ave gloriosa virginum regina, cuya escritura como se ha explicado difiere del resto de piezas, y en la cual no se puede deducir un significado mensural determinado de la irregular distribución de notas simples y ligadas. Sólo la comparación con versiones concordantes que sí usan notación mensural definida, como se señaló, permite proponer una transcripción rítmica para la pieza. El resto de las piezas responde al modelo de notación mensural franconiana, utilizando las figuras simples desde la duplex longa hasta la semibreve, notas plicadas y diversas ligaduras binarias y especialmente ternarias. Desde luego, el repertorio cum littera que preserva Toledo hace que las figuras dominantes sean la longa y la breve, mientras que las longas dobles se encuentran en ciertos finales de tenores, y las semibreves invariablemente aparecen en grupos de dos o tres, asociadas a una longa que las precede. La única pieza sine littera del manuscrito, el hoquetus In seculum, precisamente por sus características genéricas mantiene la preponderancia de notas simples, en este caso intercaladas con abundantes signos de pausa, necesarias para el efecto rítmico característico de este género. La consistente alternancia de estas longas y breves y la conformación de las ligaduras permiten una transcripción precisa de los ritmos.

Los tenores, difieren notablemente de las fuentes ibéricas concordantes. En el tenor Agmina (E-Tc 98.28 - 2, ilustración 5a) se dispone en longas simples y combinaciones de duplex longa bien diferente de las parejas longa-breve que subdividen cada longa en Huelgas, duplicando por tanto el valor de la nota (cuadruplicando en el caso de las longas dobles; Ilustración 5b).

a.

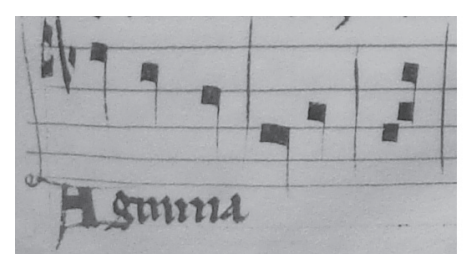

b.

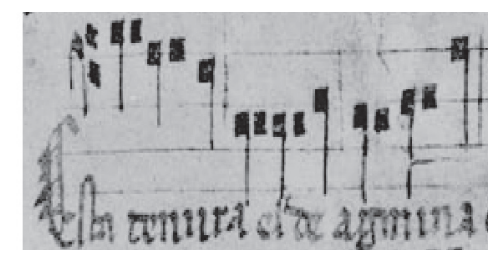

Ilustración 5. E-Tc 98.28, f.232v (a). Huelgas f.90r (b)

62 BELL, 2003: 88. 
El tenor Alleluya (E-Tc 98.28 - 3) presenta consistentemente en Huelgas caudas a la derecha en todas las longas, mientras que en E-Tc 98.28, como en Montpellier, se omiten por innecesarias (Ilustración 6).

a.

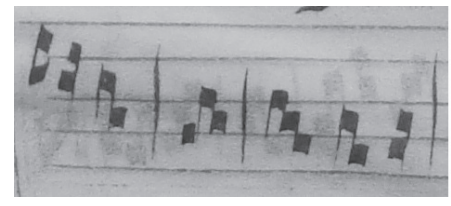

b.

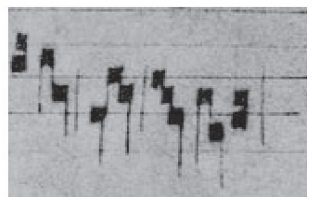

Ilustración 6. E-Tc 98.28, f.235r (a). Huelgas f.106r (b)

El tenor Domino ( $E-T c 98.28$ - 4) se realiza en el manuscrito toledano con una serie de ligaduras ternarias, como en Montpellier, muy diferente de la disposición usada en Huelgas, donde este tenor se realiza exclusivamente con longas simples durante toda la primera mitad, añadiendo ligaduras solo en la segunda mitad (Ilustración 7).

a.

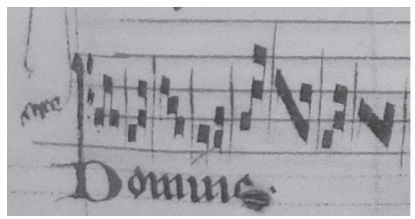

b.

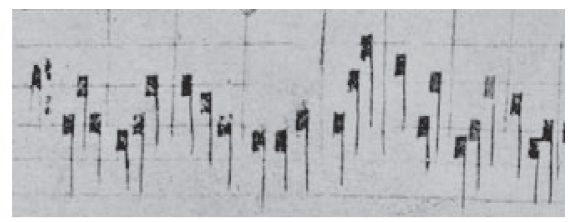

Ilustración 7. E-Tc 98.28, f.236v (a). Huelgas f. 100v (b)

El último tenor concordante con fuentes españolas es el de In seculum (E-Tc 98.28 - 6), copia exacta de las versiones de Madrid y Montpellier.

En Toledo encontramos anotado el texto que identifica cada tenor, a diferencia de lo que sucede en Las Huelgas, donde salvo en cuatro excepciones falta la indicación de este texto, y a mayor diferencia aún de lo que sucede en el manuscrito de Madrid, donde llegan a faltar incluso los propios tenores. Se ha propuesto que estas ausencias indicarían una visión pragmática del uso de manuscritos notados con música en la Península Ibérica en esta época, en la que no se consideraría relevante el texto que identifica el tenor, ${ }^{63}$ sino que únicamente se cuidaría en presentar las notas del mismo. En este aspecto, se diferencia

63 Como contraste, no obstante, consideremos la anotación que hace Juan Rodríguez en el folio 107v de Las Huelgas, ante la falta de un tenor: "la tenura fallesce aqui [...] mas sin tenura non valemos mas que valen las campannas sin cabdiello o tanto". 
E-Tc 98.28 del resto de fuentes ibéricas, y se asemeja a las principales fuentes de Francia, donde sí se identifica el tenor.

Las ligaduras binarias predominantes en Toledo corresponden al tipo cum opposita proprietate, y constan siempre de notas cuadradas individualizables, similares a las usadas en Montpellier. Difieren del modelo de binaria oblicua predominante en las concordancias con Huelgas (en donde no obstante es posible encontrar asimismo binarias con notas cuadradas). Dado que se utiliza indiferentemente una forma u otra en concordancias de la misma pieza, se puede considerar, al menos para este caso, invalida la propuesta de que los dos tipos de ligaduras c.o.p., cuadrada u oblicua, puedan apuntar a notas de diferentes valores rítmicos en cada caso. ${ }^{64}$ Ciertas binarias descendentes del hoquetus In seculum en Madrid han sido destacadas por poseer una cauda a la derecha con significado rítmico, ${ }^{65}$ concretamente, alargar la duración de la nota, iniciando así el procedimiento de hoquetus. Estas caudas en el caso de Toledo se hallan ausentes.

Las ligaduras ternarias difieren también de las usadas en concordancias españolas. En Toledo es omnipresente la ternaria en coniunctura, esto es, como una longa seguida de dos semibreves ${ }^{66}$ descenden- $^{\text {- }}$ tes, a diferencia de las ternarias con cauda descendente a la izquierda y las dos siguientes notas de forma oblicua, usadas en Huelgas (Ilustración 8).

a.

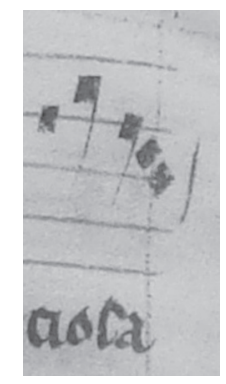

b.

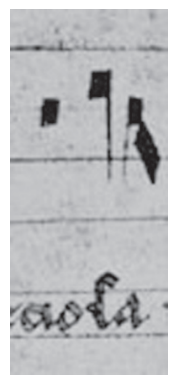

Ilustración 8. E-Tc 98.28 f. 236v (a); Huelgas f. 100v (b)

También difieren de manera notable las ternarias en Agmina malicie (E-Tc 98.28 - 2), las cuales se presentan en Toledo con propiedad y sin perfección, a diferencia de Huelgas, donde de manera más adecuada la concordancia realiza las mismas ligaduras cum opposita proprietate, y sin perfección. En

64 Como Franco de Colonia había señalado al hablar de semibrevis minor y de semibrevis maior en estas ligaduras binarias cum opposita proprietate. Véase N. BELL, 2003: 104.

65 ASENSIO, 1998: 22. 380 y ss.

66 Son los rombos denominados elmuahim por el Anónimo IV. Véase al respecto de esta denominación HAINES, 2006: 
cambio, se puede encontrar un tercer tipo diferente en la fuente concordante de GB-Lbl 2615, también usado en I-FI 29.1 y $D$-W 1099, en el cual las ternarias correspondientes de la misma pieza se presentan con propiedad y con perfección (Ilustración 9).

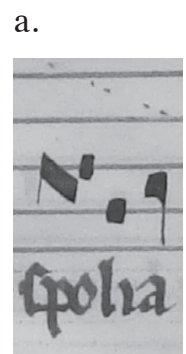

b.

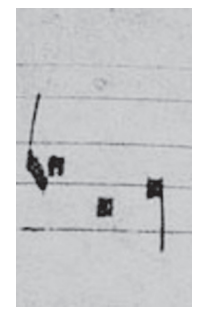

c.

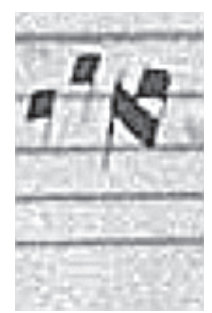

Ilustración 9. E-Tc 98.28, f. 234r (a); Huelgas f.92r (b); GB-Lbl 2615f.91r (c.)

Otra ternaria en Toledo señaladamente diferente respecto a las usadas en Huelgas es la que se observa en Res nova mirabilis. En Huelgas se usa un tipo muy específico que consiste en una primera nota c.o.p. seguida de dos notas en ligadura oblicua. En el caso de Toledo, se utiliza un tipo más común de longa seguida de dos semibreves (Ilustración 10), como sucede en Montpellier.

a.

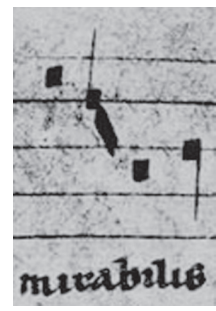

b.

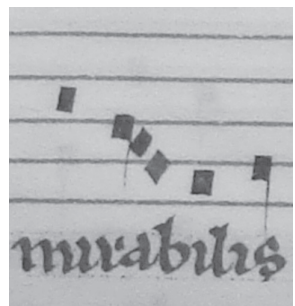

Ilustración 10. Huelgas f. 105v (a); E-Tc 98.28, f. 234v (b)

Las plicas tienen un carácter ornamental en el repertorio de Notre Dame, lo cual se refleja en el mero hecho del diferente número de notas en la melodía que representan, notas en principio subordinadas en importancia respecto a la nota principal a la que se unen. En nuestro caso, al comparar las versiones de las mismas piezas en Toledo y Huelgas, se observa que las concordancias de Las Huelgas utilizan en mayor medida las plicas que en Toledo, cuyas melodías resultan simplificadas, similares a las versiones de las mismas piezas en Montpellier o Bamberg. Esto se puede comprobar por ejemplo en las melodías de Agmina milicie ( $\mathrm{n}^{\circ} 2$ ) y Res nova mirabilis / Virgo decus castitatis ( $\mathrm{n}^{\circ} 3$ ), y en menor medida en la 
melodía de Ave gloriosa mater salvatoris ( $\left.\mathrm{n}^{\circ} 4\right)$. Se puede así respaldar la idea de que el repertorio, en el cual abundan las plicas, de Las Huelgas, representa un intento por parte del copista de plasmar por escrito una práctica de interpretación peculiar, que en otras fuentes no se refleja, quizás dando una pista de unas prácticas locales de adorno de melodías básicas a base de notas añadidas en forma de plicas. La ausencia de estas plicas en las fuentes concordantes puede ciertamente indicar prácticas interpretativas diferentes, quizás menos ornamentadas.

En cuanto a la ejecución en el trazo, las plicas de Toledo muestran un aspecto avanzado respecto al de fuentes anteriores como los manuscritos de Florencia o de Wolfenbüttel, los cuales dibujan las cabezas de las notas redondeadas, mientras que las cabezas de las notas plicadas en Toledo siguen la tendencia ya observada en Las Huelgas a cabezas cuadradas con una visible inclinación descendente hacia la derecha.

En resumen, el códice 98-28 de la Biblioteca Capitular de Toledo constituye un ejemplar tardío, pero correspondiente a la corriente principal, de lo que fueron los manuscritos creados para transmitir el repertorio asociado a la Escuela de Notre Dame. Su presencia en España, y la inclusión en el manuscrito de una de las escasas copias del hoquetus In seculum, atribuído tradicionalmente a un autor hispano, inducía a suponer una confección del documento en algún centro de producción español. Aunque no es extraña la tradición polifónica de la Escuela de Notre Dame en la Península Ibérica, hemos visto que en el caso del manuscrito de Toledo que nos ocupa, la tipología de la notación musical, precisa y a la vez concisa, se diferencia de los testimonios concordantes hasta ahora conocidos en España, y adscritos con mayor o menor seguridad a una producción autóctona. Y esto es así no únicamente por su confección, sino también por el distinto uso de los símbolos musicales que delatan una conceptualización igualmente distinta del lenguaje musical escrito por parte del amanuense. Asociando estos hechos con la caracterización de la escritura textual, que presenta rasgos propios de la producción francesa de escritura gótica, nos obliga a proponer un origen francés del documento.

En cuanto al contenido musical, si bien tres piezas concuerdan con el códice de Las Huelgas, y una cuarta, el hoquetus In seculum, lo hace con el códice de Madrid, son concordancias muy comunes con el resto de las fuentes europeas, en especial con las fuentes principales como son Montpellier, Bamberg, La Clayette o Florencia. Unido esto a la diferente ejecución material que se constata de estas piezas en Huelgas y Madrid, no podemos sino reafirmarnos en la hipótesis de que no existe una especial relación del documento con la producción española, sino que más bien se trata de una copia realizada en el contexto de la producción francesa.

A la vista de estos datos, proponemos que E-Tc 98.28 es un manuscrito realizado con probabilidad en Francia, en un entorno de copistas musicales experimentados, y en una fecha tardía respecto a la producción principal del repertorio parisino, quizás hacia 1300, como tarde en el primer tercio del siglo XIV. El conjunto de motetes, con textos diversos para todas las voces, y especialmente la presencia de un texto no localizado hasta el momento en otra fuente (Agmina malicie, en E-Tc 98.28 - 2), podría indicar 
una recopilación de repertorio en época avanzada, lo que apoyaría esta datación tardía. Se podría incluso calificar este manuscrito como "copia terminal", pues presenta piezas que ya no fueron copiadas posteriormente (como la citada voz Agmina malicie), o versiones depuradas y pulcramente copiadas, como el mismo hoquetus In seculum. El documento podría ser seguramente una copia para uso musical, dado que los cambios de folio funcionan perfectamente coordinados en las voces. El amen final en el caso particular del conductus monofónico que abre la colección, podría indicar un posible uso litúrgico para esta pieza, lo cual indicaría una asociación por temática y por el resto de indicios a un ambiente monástico.

La llegada a suelo español del manuscrito es algo que queda por dilucidar. Admitiendo el origen francés, bien pudiera haber sido importado por uno de sus anteriores poseedores, alguien ligado a las casas cistercienses de la zona de Toledo, o algún miembro de la alta jerarquía eclesiástica, en alguno de sus viajes por Francia o Italia. En los años anteriores a aquellos en que vivieron los únicos poseedores del documento que conocemos, los anteriormente citados Diego y Vasco Rodríguez de Guzmán, destacan personajes contemporáneos a la posible realización del documento, como el arzobispo mozárabe de Toledo Gonzalo Pétrez († 1299), quien estudió en París junto con don Sancho, hijo de Fernando III de Castilla, además de cursar Derecho en Padua (de cuya universidad llegó a ser rector), y Teología en el Studium Curiae de Orvieto. ${ }^{67}$ Personaje de notables dotes intelectuales, el rey Alfonso X le confió responsabilidades importantes, y lo hizo participar en la redacción de Las Partidas, su más notable recopilación legal. Una persona como el arzobispo Pétrez, poderosa y con altas inquietudes culturales, que mantuvo personalmente un taller de traductores y llegó a impulsar un proyecto personal de Estudios Generales en Toledo, legando una gran cantidad de libros a su muerte (libros de derecho, teología, patrística, filosofía, clásicos latinos, traducciones del árabe, del griego, astronomía, ciencias...) a la Biblioteca Capitular de Toledo, podría perfectamente haber sido el tipo de persona responsable de la llegada del manuscrito que hemos presentado, al entorno de la ciudad en la que hoy se conserva.

\section{BIBLIOGRAFÍA}

Analecta Hymnica Medii Aevi, 21, ed. C. BLUME \& G. M. DREVES (Leipzig, 1886-1922)

ANDERSON, Gordon A. "A Small Collection of Notre Dame Motets ca. 1215-1235." Journal of the American Musicological Society 22, no. 2 (1969): 157 - 196.

ANDERSON, Gordon A. "Clausulae or Transcribed-Motets in the Florence Manuscript?" Acta Musicologica 42 (1970): 109-128.

ANDERSON, Gordon A. "Thirteenth-Century Conductus: Obiter Dicta.” The Musical Quarterly 58, no. 3 (1972): $349-364$.

ANDERSON, Gordon A. "The Rhythm of 'Cum Littera' Sections of Polyphonic Conductus in Mensural Sources.” Journal of the American Musicological Society 26, no. 2 (1973): 288 - 304.

67 FERNÁNDEZ GONZÁLEZ, 2003: 84. 
ANDERSON, Gordon A. "The Rhythm of the Monophonic Conductus in the Florence Manuscript As Indicated in Parallel Sources in Mensural Notation." Journal of the American Musicological Society 31, no. 3 (1978): 480 - 489.

ANGLÉS, Higini. El Còdex Musical de Las Huelgas (Música a Veus Dels Segles XIII - XIV): Introducció, Facsímil i Transcripció. Barcelona: Publicacions del Departament de Música de la Biblioteca de Catalunya, vi (3 vols.), 1931.

ASENSIO, Juan Carlos. “Aproximación Al Hoquetus In Seculum.” Anuario Musical 53 (1998): 13-28. ASENSIO, Juan Carlos. “Contrafacta y Préstamos En Conductus y Motetes Del Ms. Madrid 20486.” En Fuentes Musicales En La Península Ibérica, ca. 1250-ca. 1550 : Actas Del Coloquio Internacional, Lleida, 1-3 Abril 1996 / Edición a Cargo de Maricarmen Gómez, Màrius Bernadó (2002): 83-96.

AUBREY, Elizabeth. "The Dialectic Between Occitania and France in the Thirteenth Century." Early Music History 16 (1997): 1 - 53.

BALTZER, Rebecca A. "Why Marian Motets on non-Marian Tenors?" En Music in Medieval Europe: Studies in Honour of Bryan Gillingham, ed. por Terence Bailey y Alma Santosuosso, 122. Hants: Ashgate Publishing, 2007.

BELL, Nicolas. The Las Huelgas Music Codex. Madrid: Testimonio, 2003.

BELTRÁN DE HEREDIA, Vicente. Cartulario de La Universidad de Salamanca, Vol. 1. Salamanca: Universidad de Salamanca, 1970.

BENT, Margaret. "New and Little-Known Fragments of English Medieval Polyphony." Journal of the American Musicological Society 21, no. 2 (1968): 137 - 156.

BIEZEN, Jan van, and Kees VelLEKoop. "Aspects of Stroke Notation in the Gruuthuse Manuscript and Other Sources." Tijdschrift van de Vereniging Voor Nederlandse Muziekgeschiedenis 34, no. 1 (1984): $3-25$.

BRANNER, Robert. "Manuscript-Makers in Mid-Thirteenth Century Paris." The Art Bulletin 48, no. 1 (1966): $65-67$.

DALGLISH, William. "The Origin of the Hocket." Journal of the American Musicological Society 31, no. 1 (1978): 3 - 20.

DUBY, Georges. La Época de Las Catedrales. $5^{\text {a }}$ ed. Madrid: Cátedra, 2005.

ELLINWOOD, Leonard. “The 'Conductus'.” The Musical Quarterly 27, no. 2 (1941): 165 - 204.

EVERIST, Mark. "Music and Theory in Late Thirteenth-Century Paris: The Manuscript Paris, Bibliothèque Nationale, Fonds Lat. 11266.” Royal Musical Association Research Chronicle 17 (1981): 52-64.

EVERIST, Mark. "Reception and Recomposition in the Polyphonic 'Conductus Cum Caudis': The Metz Fragment.” Journal of the Royal Musical Association 125, no. 2 (2000): 135 - 163.

EVERIST, Mark. French Motets in the Thirteenth Century: Music, Poetry and Genre. Cambridge: Cambridge University Press, 2004.

FASSLER, Margot E. "Who Was Adam of St. Victor? The Evidence of the Sequence Manuscripts." Journal of the American Musicological Society 37, no. 2 (1984): 233 - 269. 
FASSLER, Margot E. "The Role of the Parisian Sequence in the Evolution of Notre-Dame Polyphony." Speculum 62, no. 2 (1987): 345 - 374.

FERNÁNDEZ GONZÁLEZ, Demetrio, Gonzalo Ruiz de Toledo, Señor de Orgaz: († 1323). Toledo: I.T. San Ildefonso, 2003

FULLER, Sarah. "Hidden Polyphony, A Reappraisal." Journal of the American Musicological Society 24, no. 2 (1971): 169 - 192.

GAUTIER, León. Oeuvres Poétiques d'Adam de S. Victor. Paris: Julien, Lanier, Cosnard et Co., 1894.

GÓMEZ MUNTANÉ, Maricarmen, ed. Historia de La Música En España e Hispanoamérica, Vol. I. De Los Orígenes Hasta c. 1470. Madrid: Fondo de Cultura Económica, 2009.

GRABOIS, Aryeh, "Militia and Malitia: The Bernardine Vision of Chivalry", en The Second Crusade and the Cistercians, Michael Gervers, ed. New York: Palgrave Macmillan, 1992.

GILLINGHAM, Bryan. "British Library MS Egerton 945: Further Evidence for a Mensural Interpretation of Sequences." Music \& Letters 61, no. 1 (1980): 50 - 59.

GILLINGHAM, Bryan. “A New Etiology and Etymology for the Conductus.” The Musical Quarterly 75, no. 1 (1991): 59 - 73.

GONZÁLVEZ RUIZ, Ramón. Ysabel, la Reina Católica. Una mirada desde la Catedral Primada. Toledo: Arzobispado de Toledo, 2005.

HAGGH, Barbara, and Michel HUGLO. "Magnus Liber: Maius Munus. Origine et Destinée Du Manuscrit F.” Revue de Musicologie 90, no. 2 (2004): 193-230.

HAINES, John. "Anonymous IV as an Informant on the Craft of Music Writing." The Journal of Musicology 23, no. 3 (2006): 375 - 425.

HAINES, John. “The Origins of the Musical Staff.” The Musical Quarterly 91, no. 3 (2008): 327 - 378.

HUGLO, Michel. "Notated Performance Practices in Parisian Chant Manuscripts of the Thirteenth Century." En Plainsong in the Age of Polyphony, ed. por Thomas Forrest Kelly. Cambridge: Cambridge University Press, 1991.

HUOT, Sylvia. Allegorical Play in the Old French Motet: The Sacred and the Profane in Thirteenth Century. Stanford: Stanford University Press, 1997.

JEANROY, Alfred, Louis Marie BRANDIN, and Pierre AUBRY. Lais et Descorts Français Du XIIIe Siècle. Paris: H. Welter, 1901.

JEFFERY, Peter. “A Four-Part 'In Seculum' Hocket and a Mensural Sequence in an Unknown Fragment.” Journal of the American Musicological Society 37, no. 1 (1984): 1 - 48.

KNAPP, Janet. "Two Xiii Century Treatises on Modal Rhythm and the Discant: Discantus Positio Vulgaris De Musica Libellus (Anonymous VII)." Journal of Music Theory 6, no. 2 (1962): $200-215$.

KNAPP, Janet. "Polyphony at Notre Dame of Paris." In New Oxford History of Music. Oxford: Oxford University Press, 1990.

KNAPP, Janet. "Conductus, 2. Notre Dame of Paris", en www.oxfordmusiconline.com (acceso el 16 de Mayo de 2010). 
NORWOOD, Patricia P. "Evidence Concerning the Provenance of the Bamberg Codex." The Journal of Musicology 8, no. 4 (1990): 491 - 504.

PAGE, Christopher. “The Performance of Ars Antiqua Motets.” Early Music 16, no. 2 (1988): 147 - 164. PARRISH, Carl. The Notation of Medieval Music. New York: Pendragon Press, 1978.

PAUL, Jacques. Historia Intelectual Del Occidente Medieval. Madrid: Cátedra, 2003.

PAYNE, Thomas B. “'Associa Tecum in Patria': A Newly Identified Organum Trope by Philip the Chancellor.” Journal of the American Musicological Society 39, no. 2 (1986): 233 - 254.

PESCE, Dolores. "The Significance of Text in Thirteenth-Century Latin Motets." Acta Musicologica 58, no. 1 (1986): 91-117.

PESCE, Dolores. "A Revised View of the Thirteenth-Century Latin Double Motet.” Journal of the American Musicological Society 40, no. 3 (1987): 405 - 442.

RECKOW, Fritz. Der Musiktraktat Des Anonymous 4. Edited by Franz Steiner. Wiesbaden: Beihefte zum Archiv für Musikwissenschaft (vols. 4-5), 1967.

RICO, Gilles. "Music in the Arts Faculty of Paris in the Thirteenth and Early Fourteenth Centuries." Tesis Doctoral, Oxford University, 2005.

RILLON-MARNE, Anne-Zoé. “Philippe Le Chancelier et Son Euvre : Étude Sur L'élaboration D’une Poétique Musicale.” Tesis Doctoral, Université de Poitiers, 2008.

SANDON, Nick. "Mary, Meditations, Monks and Music: Poetry, Prose, Processions and Plagues in a Durham Cathedral Manuscript.” Early Music 10, no. 1 (1982): 43 - 55.

SCHRADE, Leo. "Unknown Motets in a Recovered Thirteenth-Century Manuscript." Speculum 30, no. 3 (1955): $393-412$.

STEINER, Ruth. “Some Monophonic Latin Songs Composed Around 1200.” The Musical Quarterly 52, no. 1 (1966): 56 - 70.

TREITLER, Leo. “The Polyphony of St. Martial.” Journal of the American Musicological Society 17, no. 1 (1964): $29-42$.

VEGA CERNUDA, Daniel. "Repertorio Español En El Códice de Las Huelgas.” Revista de Musicología XIII (1990): 422-449.

WOLINSKI, Mary Elizabeth, and Barbara HAGGH. "Two 13th-century Hockets on Manere Recovered.” Early Music XXXVIII, no. 1 (2010): 43-58.

WRIGHT, Craig. Music and Ceremony at Notre Dame of Paris, 500-1550. Cambridge: Cambridge University Press, 1989.

YUDKIN, Jeremy. The Music Treatise of Anonymous IV, A New Translation. Musicological Studies \& Documents, 41. Hänssler-Verlag (Neuhausen-Stuttgart): American Institute of Musicology, 1985. 
Facsímil de $E$-Tc 98.28

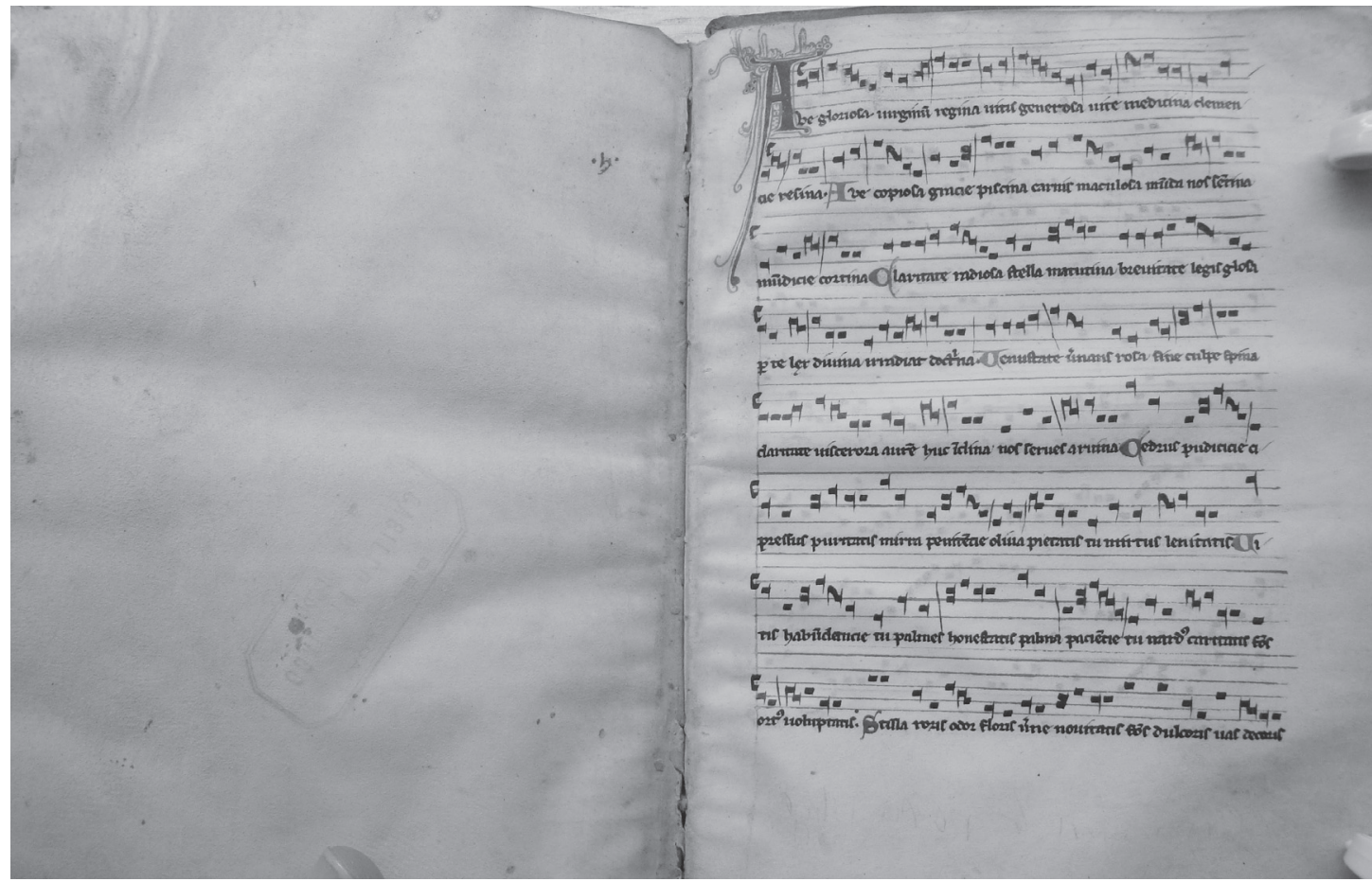

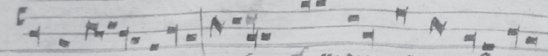

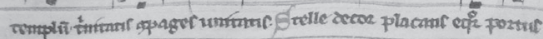

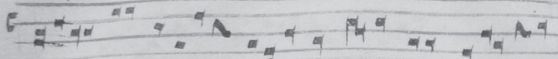

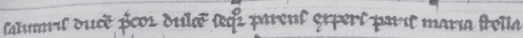

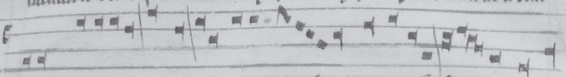
ขnatr. O

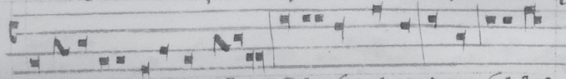

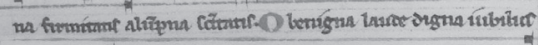
E. .9" - I"

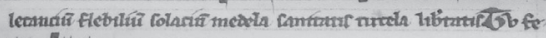

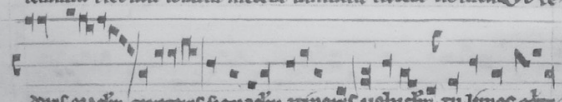

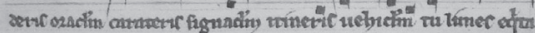

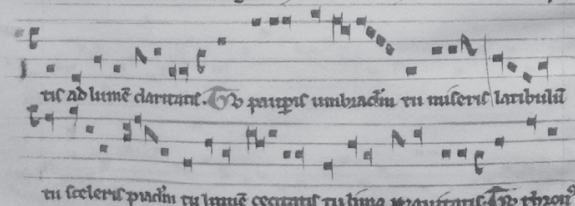

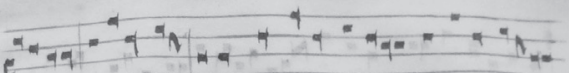

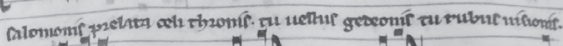
$e^{4}$

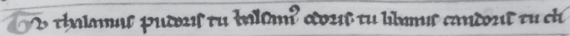

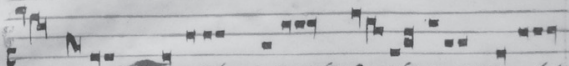

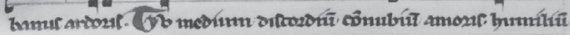

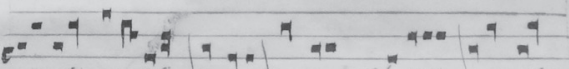

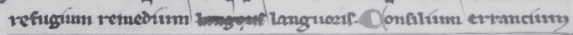

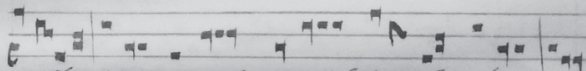

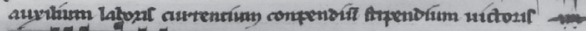
$e^{-79}+\ldots$

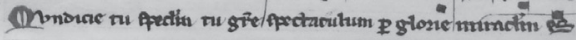

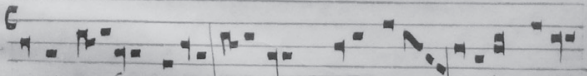

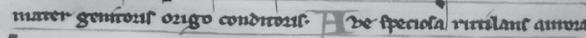

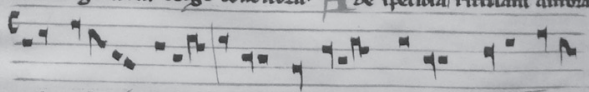

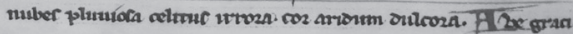



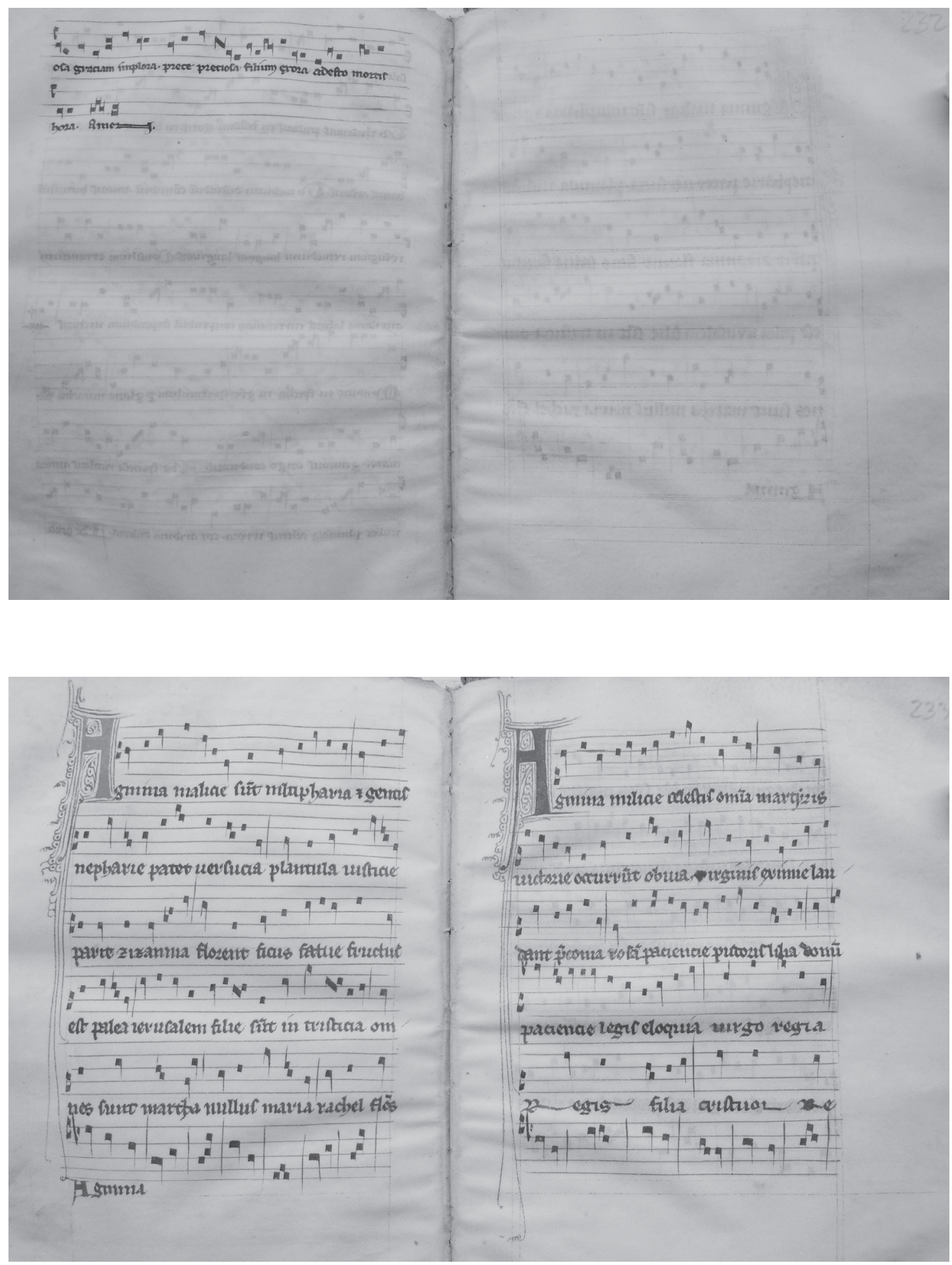

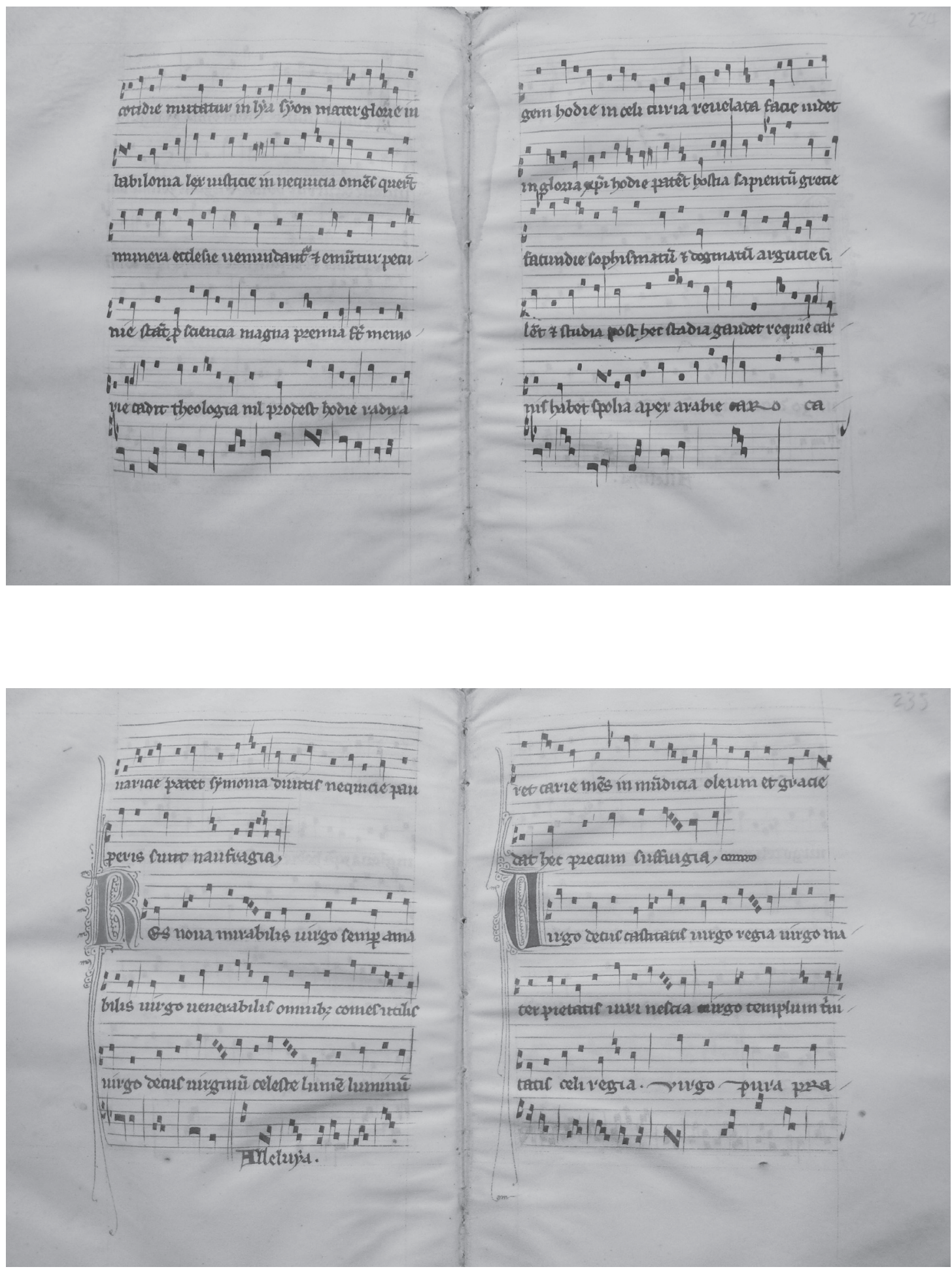
if. 1. 1.1.9.1.9 ane taus gencum firmaq" qee fixtumu

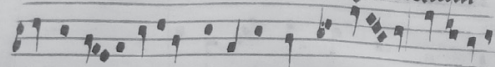

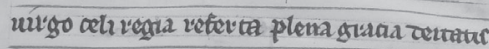
$69+1 \ldots \ldots$ pluma urigo remqer omaza zam belenía

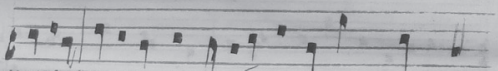

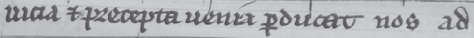

\subsection{7}

starcara.

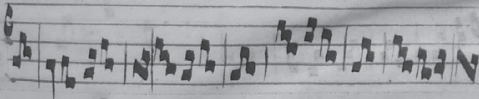

$\div 4.4 .9 .1,1 \% 1$ urtatis tele uar. nos enitnians a peota

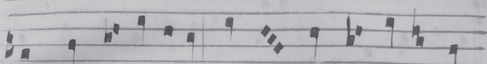
tis pel futtiagra, per te nobis pene ta $\because 4.9,9.94$

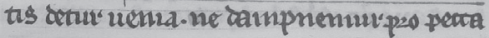

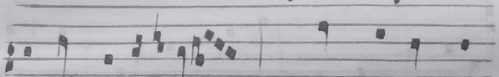
tus in muctia. Seb firuamux

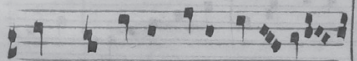
cum beatus cell ofloza

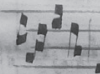

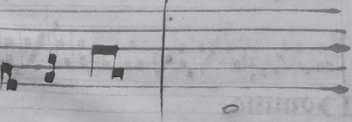

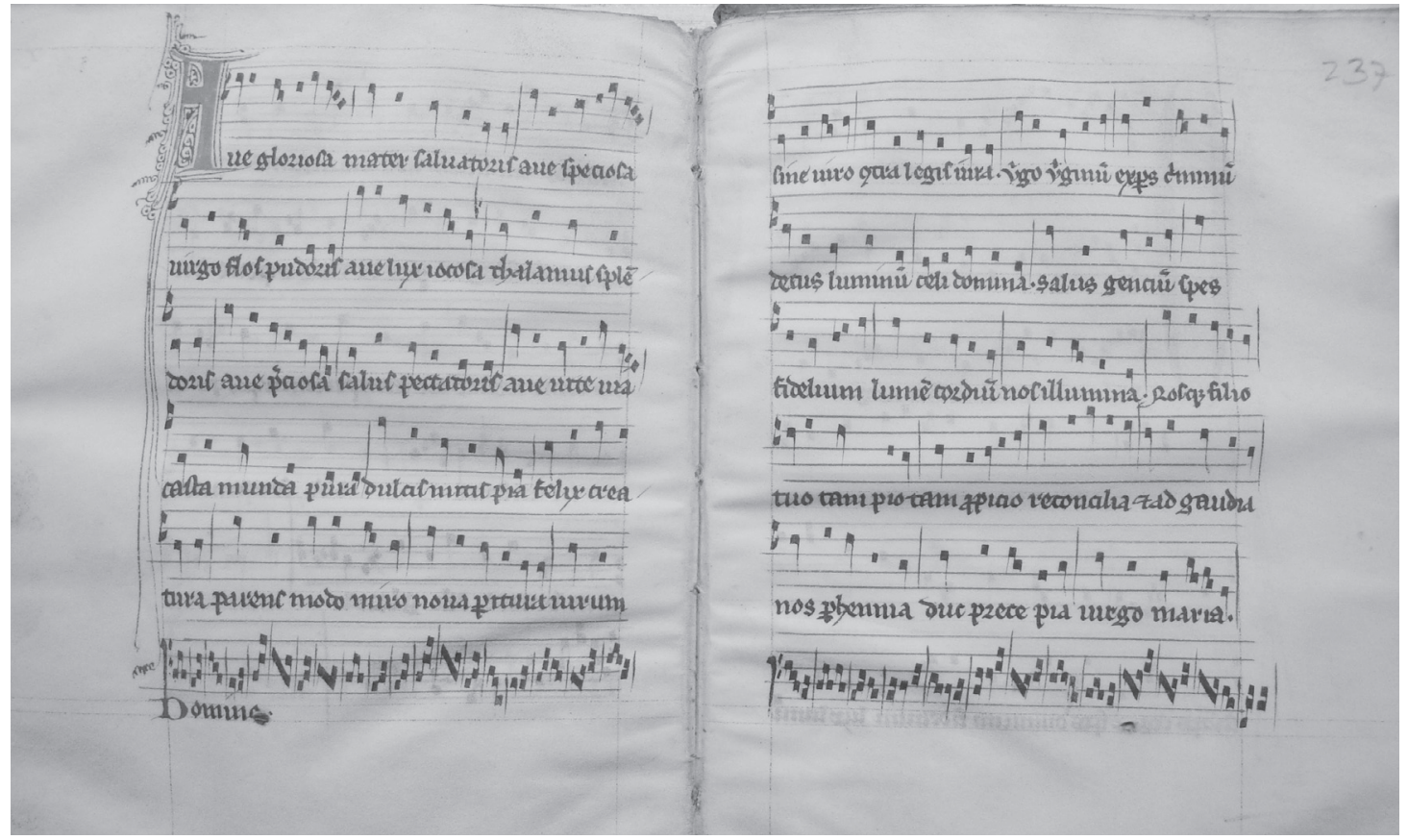



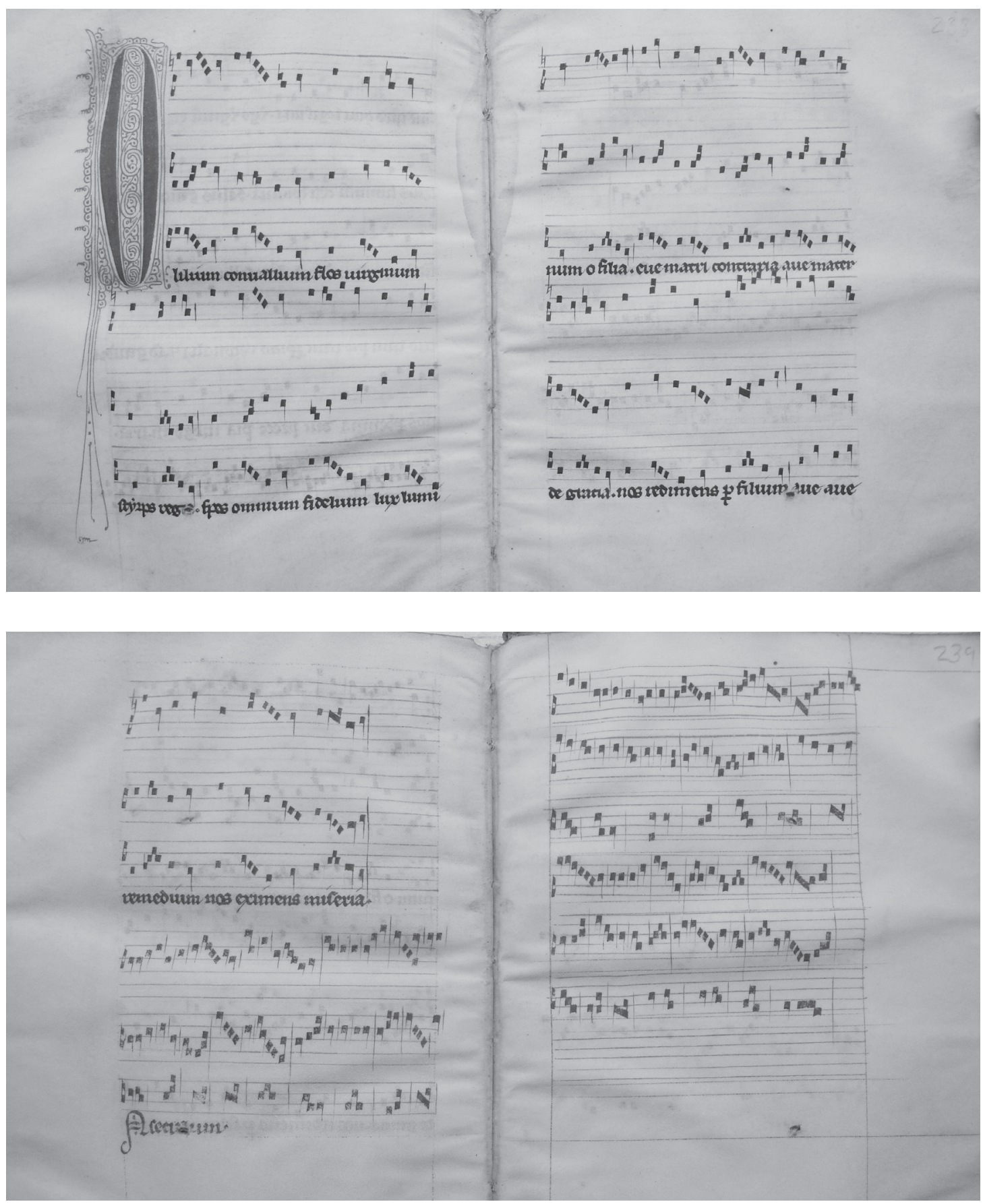

Recibido: 14/10/2011

Aceptado: 04/06/2013 